\title{
Impression Management and the Biasing of Executive Pay Benchmarks: A Dynamic Analysis
}

\author{
Mathijs de Vaan \& Thomas A. DiPrete \\ Department of Sociology \\ Columbia University, New York, NY, USA \\ md2999@columbia.edu \& tad61@columbia.edu
}

This research has been supported in part by a grant from the Russell Sage Foundation and by the National Science Foundation under Grant No. SES-1359666. 


\section{Abstract}

We study the selection of peers into compensation peer groups reported by U.S. corporations. Securities and Exchange Commission (SEC) regulation requires firms to report these peer groups which are used by investors and shareholders to benchmark the compensation of CEOs. Building on a novel, dynamic analysis of more than 1,400 compensation peer groups since 2006, this paper presents new evidence that compensation peer groups are biased upwards relative to neutrally chosen "natural" peer groups. This upward bias is masked by several factors including normative selection on other criteria than compensation and the strong negative relationship between bias and the percentile at the named peer group at which the CEO is compensated. We find that adjustments to compensation peer groups are often better explained as bias-maintaining impression management than as structural adjustments to align peer groups more closely with the normative principles for peer group selection. We also find that peer group bias cannot generally be explained away as a reward for CEO talent. Our research suggests that although the SEC regulation was intended to minimize rent extraction, it has given firms a tool to manage impressions of shareholders and justify excessive pay. 


\section{Introduction}

It is now well known that rising income inequality in the U.S. has, in recent decades, been driven by changes in the top of the income distribution and particularly in the pay of "supermanagers" (Piketty, 2014), who dominate the top 0.1\% of this distribution (Bakija, Cole, and Heim, 2010). Average CEO compensation increased from $\$ 625,000$ to $\$ 9,840,000$ - or $12 \%$ per year - between 1980 and 2004. Moreover, despite very slow growth in market capitalization in recent years, CEO pay has continued to increase. Figure 1 shows the change in CEO pay between 2006 and 2012 for the constituents of the S\&P 1500 and the market capitalization for that same sample. The median compensation of CEOs in the S\&P 1500 has increased by 57\% from 2006 to 2012, while the median market capitalization has increased by only 7\%. A growing research literature, as well as extensive copy in the broader media, continues to debate the explanation for this spectacular rise.

\section{[Figure 1 about here.]}

This literature is dominated by two major competing theories (Murphy, 1999; Bertrand, 2009; Frydman and Jenter, 2010). The "pay for performance" theory asserts that the market determines what a CEO is worth and it does so efficiently. According to this theory, the market addresses the principal-agent problem by providing adequate incentives to align the CEOs behavior with shareholder interests. The competing "managerial power" theory asserts that CEOs use their power to take advantage of market imperfections and inadequate corporate governance to raise CEO pay above the level that would be achieved purely through market forces. Shareholders and perhaps also consumers end up paying for the excess compensation through a process that amounts to rent extraction.

The debate about executive compensation remains lively because of the difficulty of constructing definitive tests that would adjudicate between the two hypotheses. A "bottom line" test might examine the levels and distribution of compensation, and determine whether it is consistent with the predictions of market theory. Some scholars argue that the rapid rise of CEO pay, the high pay of American CEOs relative to their counterparts in other industrialized countries, or the weak correlation between executive compensation and corporate performance undermine an explanation based on pure market forces (Stiglitz, 
2012; Piketty, 2014). Other scholars disagree and propose mechanisms by which neutral markets could give rise to the current levels and distribution of pay as well as the high annual rate of increase during the past two decades (Conyon, 2014; Gabaix and Landier, 2008; Gabaix, Landier, and Sauvagnat, 2014; Fernandes, Ferreira, Matos, and Murphy, 2013). ${ }^{1}$

This paper follows an alternative strategy for adjudicating between the two competing hypotheses of managerial power and pay for performance. We aim to identify microstrategies by which executives are able to influence the pay setting process in ways that undermine market forces. These market forces are assumed to provide a counterweight to attempts at self-serving behavior by executives, but prior research has shown that strategic action by executives may severely reduce market efficiency. This research has addressed various forms of strategic action such as the timing or backdating of stock options and has provided evidence for the operation of executive power over compensation (Bebchuk and Fried, 2005; Lie, 2005). In this paper, we look for evidence that corporations attempt to disguise market signals about appropriate compensation for their executives as part of a process of impression management directed at shareholders and other interested stakeholders. The specific process that we study is the compensation benchmarking process.

We argue that executive power over compensation is not a mechanical consequence of their decision-making power in the company. While executives have wide ranging decisionmaking power, their discretion clearly does not include setting their own pay. In formal terms, CEO pay is set by the board of directors after consultation with the board's compensation committee and outside consultants. This pay-setting process is also mindful of various constituencies that pay attention to this decision, not least of which are the company's shareholders as well as watchdog agencies such as Glass Lewis and Institutional Shareholder Services (ISS) who influence the voting behavior of institutional sharehold-

\footnotetext{
${ }^{1}$ For example, Fernandes et al. (2013) recently argued that much of the large pay gap between American and European firms - in their sample it is an $88 \%$ premium according to Model 2 of Table 3, can be statistically explained in terms of compositional differences in the extent of insider ownership - which depresses pay -, and institutional ownership and board independence - which enhances pay. Simply put, American companies tend to have greater levels of institutional ownership and greater fractions of independent directors. Fernandes et al. (2013) interpret this pattern to mean that institutional owners and independent boards demand higher corporate performance and incentivize CEOs to work harder and take risks to achieve this performance in exchange for higher risk-compensated compensation. An alternative interpretation is that these governance characteristics are associated with higher levels of executive rent.
} 
ers. This process of pay setting is rationalized to conform to environmental expectations that companies use procedures to ensure that executive pay is a rational response to labor market conditions and to the company's own market situation. Moreover, while it is often argued that executives can influence the recommendations of compensation consultants and of compensation committees, this influence is still constrained by the need for at least a strong impression that the decision is a legitimate response to market forces. Therefore, executive power over pay would necessarily involve an ability to manage impressions among the major stakeholders that the compensation decision conforms with the realities of the market. We argue that an important strategy by which the impression is managed concerns the companies who are asserted as peers, the compensation of the executives of these peers, and the pay point in this distribution at which the company's executive is compensated. Market forces may well dictate that a high quality CEO's compensation should be in the right tail of the peer distribution, and one would expect companies to make this argument when the company's performance and market condition support it. However, when companies instead assert a set of peers that upwardly bias the benchmark and then assert a pay point that is close to the middle of the resulting distribution, we argue that the resulting disguise of the compensation level provides evidence of executive power. By making the benchmarking process seem rational and legitimate, companies are able to influence impressions of major stakeholders and make otherwise controversial practices seem normal.

In some respects, this "process" test suffers from the same interpretive ambiguity and disagreement that surrounds the "bottom line" evidence of excessive pay noted above. While several scholars argue on theoretical grounds that benchmarking is an efficient way to set CEO compensation (Holmstrom and Kaplan, 2003; Bizjak, Lemmon, and Naveen, 2008; Albuquerque, De Franco, and Verdi, 2013), a number of studies have determined that the selection of compensation peers is biased in ways that disguise the "market price" for a CEO's compensation. Specifically, while firms typically include normatively appropriate companies - i.e., companies of roughly the same size in the same industry - in their peer groups, they also frequently include "aspiration peers" and companies that compensate their CEO at higher levels than one would predict based on the company's size and industry. So despite tendencies towards "normal" peer selection, firms have enough discretion to 
allow for a positive bias in the compensation profiles of CEOs of selected peers (Faulkender and Yang, 2010, 2013; Pittinsky and DiPrete, 2013; Albuquerque, De Franco, and Verdi, 2013). Moreover, even though the SEC has required public disclosure of the benchmarking process since 2006, studies have found little evidence that SEC "sunshine" is reducing the aggregate bias over time (Pittinsky and DiPrete, 2013; Faulkender and Yang, 2013). This evidence supports the interpretation that biased peer groups are a form of self-serving behavior by CEOs and their allies on boards of directors to produce and justify excessive compensation for executives.

Countering this evidence for manipulation of the benchmarking process are arguments that this apparent bias in the benchmarking process is not real. In the world of business, defense of the neutrality of benchmarking comes from compensation consultants such as Ira Kay, a managing director of Pay Governance, who recently asserted in a public debate about executive compensation that benchmarking produces an accurate market price for executives (Smith, 2014). A more academic defense comes from Albuquerque et al. (2013), who argues that the apparent compensation bias in peer groups selected by disclosing firms is actually an intentional adjustment by compensation committees to take account of "unobserved" CEO talent. They describe the compensation difference between the selected peer group and a counterfactual peer group that disregards talent considerations as a "peer pay effect," and claim that it is a "reward" for talent. From this perspective, the board of directors would appear to use aspiration peer groups as a way to assert their high evaluation of the quality of the firm's CEO and forestall negative reaction by shareholders, investors, and journalists to what might otherwise appear to be overly generous CEO pay (Wade et al., 1997; Zajac and Westphal, 1995; Westphal et al., 2012).

In this paper, we adjudicate among these competing explanations by studying the dynamics of compensation peer groups to search for evidence of peer group selection that is consistent either with market mechanisms or with self-serving behavior by executives. The use of dynamic data for the study of compensation peer group bias has several advantages. First, it allows us to analyze decisions to drop specific existing peers or add specific new ones, and to assess whether these decisions are consistent with normative peer selection principles or whether they appear to be self-serving. Second, by studying the 
changes in peer groups, we can exploit the argument that talent is a relatively stable and durable characteristic (Bertrand and Schoar, 2003; Graham et al., 2011) and that the $a d$ dition or removal of peers should not be primarily motivated by talent considerations if there was no CEO turnover in either the focal firm or in the added or removed peer firm. In other words, the efficient-market hypothesis would suggest that if the "peer pay effect" can be accounted for by talent, then change in the peer group should not be motivated by the level of compensation of CEOs in peer firms and/or potential peer firms when there has been no change in the tenure of the CEO of the focal or peer company. The addition of peer firms with well paid CEOs (higher pay than the median peer in a "natural" peer group) or the removal of peer firms that fall short (compared to the median peer) in compensating their CEO, could be interpreted as evidence of the presence of a self-serving effect in the modification of peer groups, particularly in cases where the CEO of the focal firm and the $\mathrm{CEO}$ of the added or removed peer remain the same. In contrast to predictions of an efficient market theory, we develop the argument that changes in peer groups are part of a strategy of impression management by executives and their allies to make excessive compensation look market-rational. We suggest several mechanisms by which peer groups can be constructed that are legitimate and illegitimate at the same time.

We have created the most extensive longitudinal dataset of peer selection thus far compiled. Our dataset is especially valuable because it provides information about the peers that were added and removed over the years covered by our data. If CEOs are being rewarded for performance and talent, then changes to a peer group that potentially affect a CEO's pay should be driven by changes in performance, which is posited as the main indicator of CEO "talent" in the literature. Changes to a peer group that justify higher pay without being related to prior performance or to structural changes in the firm are arguably evidence of self-serving behavior on the part of CEOs. In the next two sections we will first discuss the process of benchmarking in further detail and then we will link these insights to the literature on impression management. We then present our empirical strategy and the findings that are based on this strategy. In the final sections, we discuss and summarize our findings. 


\section{Processes for Evaluating CEOs}

Corporate executives, like other workers, are presumed by believers in the efficiency of markets to operate within a labor market that aligns productive value with pay. Boards of directors of corporations routinely justify their decisions about executive compensation as being responsive to labor market realities. Economic sociologists, of course, recognize that the valuations of even routine jobs are contingent "products of social interaction" (Zuckerman, 2012). At the same time, both defenders and critics of executive pay practices recognize that the justification of executive pay is not as straightforward as it is for the production or clerical workers of the company, both because executives have so much more influence on board decisions than do secretaries, and because executive pay has climbed so rapidly relative to production workers in the past twenty-five years.

The issue of whether CEOs are paid appropriately is partly about whether executive labor markets efficiently link pay with performance. It is also about the effectiveness of recent efforts to increase the power of shareholders, e.g., through say on pay votes. The increased influence of proxy advisory organizations might on the one hand be taken as evidence that executive compensation is embedded in the social world, and emerges via a political process in the same way that collective bargaining agreements for union workers emerge from a political process. On the one hand, initiatives such as the SEC's 2006 requirement that corporations report their asserted compensation peers or the non-binding say on pay votes authorized by the 2010 Dodd-Frank Act might be taken as regulatory interventions intended to correct inefficient outcomes occurring in imperfect markets. On the other hand, the greater attention by institutional investors to executive compensation may be interpreted as evidence that market forces were pushing back on self-serving pressures from executives, thereby producing outcomes that more correctly aligned executive labor markets to shareholder interests. Indeed, the recent evidence that corporate pay practices may be more closely aligning the pay of executives to performance outcomes than they were as recently as a few years ago might be taken as further evidence that the market environments of public corporations tend towards efficient outcomes. More questionable practices such as the use of golden parachute or tax gross-ups are in decline (Schmidt and Reda, 2013), and corporations are making greater use of stock options that vest condition- 
ally on performance (typically, total shareholder return or relative TSR) rather than automatically over time, partly to avoid the possibility of a negative recommendation from the ISS concerning a "say on pay" vote (Reda and Schmidt, 2014).

Undermining this perspective, however, is the fact that these changes have not occurred with a corresponding decline in the level or growth of executive compensation, which would be expected if a fraction of executive compensation prior to the recent changes was actually a rent that was not performance-based. Unless one were to conclude that wellperforming CEOs were being underpaid enough to offset the rent paid to poorly-performing CEOs, the changing practices can simultaneously be viewed as efficient reforms forced on executive agents by shareholder principals and as exercises in impression management by boards of directors (often executives themselves) with an interest in defending and further institutionalizing the generous compensation practices at U.S. public corporations. Reflecting on the lessons of the recent financial crisis, Zuckerman (2010) argued that regulation increases market efficiency when it promotes arbitrage and learning. We see no clear connection between governance reforms and executive labor market arbitrage, which would occur if better governance procedures allowed savvy boards to seek out undervalued high quality CEOs more effectively and pay these CEOs below-market compensation. Organizational learning might well be promoted by regulatory activity if better corporate governance concerning executive compensation leads to improved corporate performance through an alignment of pay and performance. But while there is evidence for organizational learning when one examines organizational compensation policies (e.g., the decline in use of tax gross-ups), there is little evidence for learning when one analyzes aggregate compensation outcomes.

Although there is controversy about corporate pay practices and executive pay levels, there is general agreement among both companies and stakeholders that the determination of pay should involve comparisons with peer CEOs. The use of peers to evaluate the performance, quality, or worth of people or organizations is common practice in multiple settings. Student grades are evaluated vis-a-vis other students in the class or cohort, company performance is benchmarked against the performance of industry peers, and the bonuses of middle managers are set by comparing their performance with other middle managers 
within the firm. Agreement on this issue, of course, still leaves as an open question the appropriate composition of the peer group that a firm or executive should be compared against. Early scholarly debates within organization science and economics addressed the question of whether executives should be compensated based on "internal" or "external" labor markets (Roberts, 1956; Simon, 1957; DiPrete et al., 2010). Fueled by the increase of labor mobility of executives in the last decades of the 20th century, benchmarking against "a list of companies comparable to [the focal] organization" emerged as the dominant practice to set the compensation of executives (Cook, 1981, p.39).

Benchmarking against internal pay scales allows for a clear definition of the comparison group but presents the difficulty of justifying a ratio between CEO pay and other internal executives. Prior research has shown that this ratio has steadily increased over time (Bebchuk and Grinstein, 2005; Frydman and Saks, 2010) in an era when the primary justification for executive pay has been the external market. External benchmarks would seem to be more straightforward since the general criteria on which peer companies should be chosen (size, market, and possibly performance) are uncontroversial. Many firms explicitly mention the criteria that were used in defining the population of potential peers in the reports that they file annually with the SEC, and industry similarity and size similarity are most frequently mentioned. A recent report by research company Equilar shows that the vast majority of firms uses industry, market capitalization, and revenue as criteria for including a peer firm in the peer group. However, firms typically choose only subsets of the companies that would fit these criteria. The use of what appear to be nonrandom samples of "natural" peer populations, combined with the fact that companies also will sometimes select as peers CEOs from companies outside the "natural" peer population implies that firms reserve for themselves the discretion to select peers based on undisclosed characteristics (Faulkender and Yang, 2010, 2013; Pittinsky and DiPrete, 2013; Albuquerque, De Franco, and Verdi, 2013).

The idea of pay for performance suggests that better performing CEOs should be compensated higher than less-well performing CEOs. Compensation committees could place such a talented CEO closer to the right tail of the compensation distribution defined by peers of the same size and industry. However, several studies have suggested a second mech- 
anism through which a CEO can be placed among highly compensated CEOs. This mechanism is expressed by the tendency for many firms to select peers that are an upwardly biased sample of the natural peer group, in terms of the compensation of the CEOs. A peer group selection process that results in such a peer group is frequently seen as evidence of self-serving behavior by top executives who have the power to steer corporate policies away from the direction that is in the best interest of principals (i.e., the shareholders), especially in firms with relatively weak corporate governance mechanisms (Barkema and Pennings, 1998). A related version of this approach, which is referred to in the literature as "upper echelons theory," (Hambrick and Mason, 1984; Chin et al., 2013), hypothesizes that executive personalities and values are important determinants of the extent to which executives will use their considerable power as agents to favor their own financial interests over those of stockholders.

In recent years, critics of executive compensation practices have increased pressure on corporations to justify compensation in terms of executive performance. Institutional investors increasingly monitor firm behavior regarding compensation as a guideline for how they vote their shares at shareholder meetings. The Council of Institutional Investors has taken the position that executive compensation should be "transparent and tightly tied to corporate performance, create value for the long-term, and advance the company's strategic goals." ${ }^{2}$ Equilar now makes available "pay-for-performance" analytics tools. Both Glass Lewis and the ISS evaluate the governance and compensation practices of firms in the context of recommending whether institutional shareholders should vote yes in non-binding "say on pay" votes concerning executive compensation. ${ }^{3}$ While say on pay votes have overwhelmingly supported compensation decisions by the boards of directors, ${ }^{4}$ there has been a clear trend in recent years towards moving compensation practices in line with "good governance" guidelines asserted by corporate governance watchdog organizations. For example, the largest 200 corporations have steadily shifted their pay practices from the use of stock options that are not considered performance-based by the ISS to the use of performance-

\footnotetext{
${ }^{2}$ See bit.ly/1rzWT0i.

${ }^{3}$ say on pay votes were allowed for public corporations by the Dodd-Frank Wall Street Reform and Consumer Protection Act.

${ }^{4} 97$ percent of the votes were in favor of the board proposal in 2012, and 98 percent were in favor of the board proposal in 2013 .
} 
vested stock grants (Reda, 2013). Larcker et al. (2013) has found that institutional shareholders generally follow the recommendations of proxy advisory firms and also that many firms change their compensation practices in advance of say on pay votes in order to avoid a negative recommendation. In particular, the use of excise tax gross-ups has declined from $80 \%$ in 2007 to $20 \%$ in 2011 (Reda, 2013), companies also are more likely to shift to performance-vested equity compensation in advance of say on pay votes (Larcker et al., 2013).

Given that there is no significant decrease in compensation, these changes in compensation practices are consistent with arguments that executives gain resources from the environment by performing symbolic actions that enhance their legitimacy (Zott and Huy, 2007). Reform-minded observers, of course, hope that these behaviors go beyond the symbolic and reduce "excessive" CEO compensation that is not market-justified. Notably, however, these changes in pay practices have not produced any downward trend in executive compensation (Conyon, 2014). It is also notable that corporations have apparently not reduced their tendency to include "outlier" peers in the compensation peer groups that they ostensibly use to determine executive pay (Pittinsky and DiPrete, 2013; Faulkender and Yang, 2013).

\section{Managing Impressions in the Pay Setting Process}

Under conditions of perfect information, market participants are expected to set executive compensation based on the supply and demand of talent. In reality, however, market participants vary in their access to relevant information which may result in conflicting rationales and market inefficiencies. Another source of such market inefficiencies are disagreements about the evaluation criteria that should be used in the pay setting process. In particular, given the apparent differences between CEO skill sets (such as their ability to promote innovation or efficiently transform inputs into outputs), the value of these differences is often contested. Market actors operate under multiple orders of worth (Stark, 2009) and these orders of worth give rise to friction in the evaluation process. Disagreement about the basis for deciding on compensation as well as on the specific performance of the $\mathrm{CEO}$ in terms of these criteria may produce stronger negative reactions from share- 
holders, investors, and journalists if they also discover that the CEO is being paid in the right tail of his peer distribution (Wade et al., 1997; Zajac and Westphal, 1995; Westphal et al., 2012).

Boards may think that it is easier to "sell" an executive compensation package to shareholders that is roughly in the middle of a compensation distribution of carefully selected peers as opposed to the very same compensation package that is clearly in the right tail of a distribution of peers that are selected algorithmically on the basis of corporate size and industry. Shifting the compensation distribution of the peer group to the right through the careful selection of peers may itself generate a negative reaction, but this can be mitigated if the deviation from the natural peer group is not too extreme. ${ }^{5}$ All things considered, the use of a biased peer group may be seen as a low-cost manipulation if the result is a weaker negative reaction to an executive compensation package that now looks comparatively reasonable.

Examples of corporate actions intended to influence stakeholder perceptions or reactions to corporate behavior are fairly common in the literature. Several researchers have shown that when organizations face negative attention following one or multiple illegitimate acts, these organizations may try to reduce some of the attention by displaying prosocial behavior or behavior that is clearly within the boundaries of the prevailing social norm (Baron, 2001; Godfrey et al., 2009; McDonnell and King, 2013). For example, McDonnell and King (2013) find that when a boycott attracts negative media attention, organizations increase their level of public communication of socially desirable action, thereby reducing negative effects from the attention for the boycotts. In doing so, organizations use the communication of desirable action as a tool to manage the impressions of outside evaluators and to reduce the extent to which the organization is penalized by these outside evaluators for their prior illegitimate action.

Another example of impression management concerns financial reporting. Harris and Bromiley (2007) recently found that companies sometimes misrepresent their financial per-

\footnotetext{
${ }^{5}$ Another way in which the selection of well compensated peers may be seen as legitimate is when these peers come from the natural peer population. Each firm has a population of peers of size $N$ that is similar in terms of size and industry. Given that this population is larger than the number of peers that need to be selected into the peer group, firms can select a subset from this population that is smaller than $N$ and includes only those CEOs that are well compensated.
} 
formance in accounting reports when misrepresentation has a potentially positive impact on CEO compensation. They found that the probability of misrepresentation rises when the CEO receives a high percentage of his compensation in the form of stock options whose value depend upon the price of the firm's stock (Harris and Bromiley, 2007). The selection of peers with upwardly biased compensation and the practice of accounting misrepresentation manage impressions through different mechanisms: an upwardly biased compensation peer group makes a generously paid CEO look normal, while accounting misrepresentation manipulates the share price (and therefore the value of the stock options awarded to the $\mathrm{CEO}$ ) by giving the impression that the firm is performing better than it actually is. However, both strategies are similar in that they produce their effect by managing the impressions of less-involved directors, shareholders, and other interested stakeholders.

We argue that one of the pivotal factors in constructing the peer group is the compensation that a firm intends to pay its CEO. If the intended compensation of the focal CEO lies in the right tail of the compensation distribution of a natural peer group, the company will clearly have to defend why a CEO is worth that much more than the median CEO in the compensation peer group. Prior research suggests that firms are likely to argue that their CEO is better than the average CEO, because hiring a below par CEO sends out negative signals to shareholders, investors, and consumers. This work has also argued that if such a tendency holds across the board, a Lake Wobegon situation is created where all CEOs are above average (Hayes and Schaefer, 2009; DiPrete et al., 2010). While making an argument for the generous compensation of CEOs that performed exceptionally well is unlikely to receive much opposition from shareholders,${ }^{6}$ defending right tail compensation levels for CEOs that did not do better than average is likely to be met with criticism. It is arguably easier to defend the composition of an upwardly biased peer group, especially since the selection of peer groups attracts less scrutiny than does the compensation package of the firm's CEO. Therefore, we argue that moving the focal CEO pay towards the center of a benchmark distribution via the use of a biased peer group is a strategy for managing the impressions of outside evaluators. Recalling that the "peer pay effect" is the difference (e.g., at the median) between the compensation of CEO's in the named peer group versus a

\footnotetext{
${ }^{6}$ After all, this CEO increased shareholder wealth and is likely to do so in the future.
} 
peer group selected based on standard principles, we propose the following hypothesis:

H1a: Firms are more likely to exhibit a larger (smaller) peer pay effect if the CEO is compensated at higher (lower) percentiles of the natural peer group.

It follows as a statistical consequence of H1a that:

H1b: Firms where the CEO is compensated at lower (higher) percentiles of the named peer group are more likely to exhibit a larger (smaller) peer pay effect.

Firms can, of course, revise their peer groups. If a large airline has selected other large airlines as its peers, the emergence of a new large airline through merger or the disappearance of an airline through merger or bankruptcy would call for for a revision to the airline's peer group. More generally, peer groups can be revised to adjust for changes either in the selecting firm or for changes in the selected peers or potential peers. This updating provides firms with the opportunity to keep their peers aligned with their own demographics. However, firms and their CEOs may also see the yearly updating process of their peer groups as an opportunity to nudge the compensation distribution of their peer group to the right or to prevent the disappearance of a previously engineered peer pay effect through shifts in the compensation of the executives of named peers. Incremental changes to existing structures typically face less resistance than radical changes (Huy, 2002) and may therefore provide the conditions for the opportunistic dropping of an existing peer or the opportunistic selecting of a new one.

Proponents of efficient markets can point to the opportunities that peer group updating provide for better aligning the talent distribution of the compensation peer group with the talent of the focal CEO. However, many scholars have argued that executive talent, like talent in general, tends to be relatively stable for any individual over time (Bertrand and Schoar, 2003; Graham et al., 2011). Some recent efforts to estimate "talent effects" have relied on fixed effects models; these models, not surprisingly, find that fixed effects for executives are highly significant in a regression of executive compensation on longitudinal data (Graham et al., 2011). Of course, many attributes of a CEO can be stable over time in addition to talent, as Graham et al. (2011) acknowledge. Indeed, self-serving behavior (which is potentially related to personality and values (Hambrick, 2007)) may also be a stable trait 
over time and would thereby be a component of the CEO effect estimated in a fixed effects model. ${ }^{7}$

If talent is indeed a relatively stable and durable characteristic (Bertrand and Schoar, 2003; Graham et al., 2011), it would logically follow that the addition or removal of peers should not generally be motivated by talent considerations if there was no CEO turnover in either the focal firm or in the added or removed peer firm. In other words, if the original peer group was selected based on market pressures, then change in the peer group should not be motivated by the level of compensation of CEOs in peer firms and/or potential peer firms when there has been no change in the tenure of the CEO of the focal or peer company. The addition of peer firms with well paid CEOs who systematically fall on the right side of the pay distribution of a "natural" peer group, or the removal of peer firms that systematically fall on the left side of the existing peer group, could be interpreted as evidence of a self-serving effect in the modification of peer groups, particularly in cases where the CEO of the focal firm and the CEO of the added or removed peer remain the same. We test the following hypotheses to investigate possible tendencies towards self-serving behavior in the updating of peer groups:

H2a: Companies are more likely to be added as peers if the compensation of their CEOs is high relative to other potential peers.

H2b: Peers are less likely to be removed as peers if the compensation of their CEOs is high relative to other named peers.

If firms are using the peer group as a form of impression management to justify executive pay, it follows that they will favor peers whose membership in their peer group appears appropriate. Aside from the demographic characteristics of a firm that provide a normative measure of how well a potential peer "belongs", firms may also take account of structural characteristics that signal belongingness. Besides demographic characteristics such as size and industry similarity, the most basic signal of suitability is the popularity of a firm

\footnotetext{
${ }^{7}$ Albuquerque et al. (2013) propose two additional proxies for "hidden talent" in their paper. The first is the historical pay of the CEO, but they acknowledge that this can also reflect managerial power and selfserving behavior. The second additional (problematic) proxy they propose is a fixed effect for the CEO in the historical data.
} 
as a benchmark choice. Companies that have frequently been chosen as peers - with at least implicit shareholder approval for this choice - are (net of other considerations) more likely to be seen as legitimate choices because their use as compensation benchmarks conforms with the behavior of many other firms. In this sense, the old rationalization "no one was ever fired for buying IBM" may apply to the selection of peer groups as well. The use of popular peers may enhance the impression that the peer group is reasonable and that the focal CEO's pay deserves to be raised to be better aligned with "the market" as represented by the named compensation peer group. From a self-serving perspective, this strategy is attractive given that (as shown in Table 4 and Table 6) popular companies are generally larger and with better compensated CEOs. We test the inclusion of popular peers in compensation peer groups by testing the following hypothesis:

H3: Net of the standard criteria for peer selection, companies are more likely to be added and less likely to be removed as a peer if they were popular peer choices in the recent past.

Building on the idea that the selection of popular peers would allow firms to conform with prevalent selection practices, we argue that the favoring of popular peers may sometimes be used to mask deviant behavior. In particular, popularity of peers may provide a buffer for the selection of peers that are deviant vis-a-vis natural peers in terms of the compensation received by their CEO. For example, while the addition of a generously paid CEO to the peer group may raise a red flag for some stakeholders, the popularity of this firm as a compensation peer choice may blunt the impact of this negative attention. Interestingly, while both peer popularity and peer compensation should be regarded as illegitimate selection criteria when constructing a peer group, the fact that the adoption of popular behavior typically implies norm conformity might offset the illegitimacy of using compensation as a selection criterion. The same process of masking deviant behavior through the favoring of popular choices is applicable to the removal of compensation peers: peer CEOs with relatively low pay will be removed especially when they are unpopular because the shedding of unpopular peers appears to imply norm conformity. Our expectation is that the effect of popularity should be greater on choices that are at most risk of appearing illegitimate. For the addition of peers, the risky choices involve peers with more highly compensated CEOs. Therefore we expect that the effect of popularity will be larger for 
potential peers with higher compensated CEOs than for potential peers with lower compensated CEOs. For the removal of peers, we expect the reverse. It is the removal of firms with low-compensated CEOs that potentially raises red flags, and so we expect that popularity's effect (the rise in removal probability for unpopular firms) will be relatively large in the group of peers that have relatively low-compensated CEOs. We express these expectation in the following hypotheses:

H4a: The effect of popularity on adding a potential peer will be larger for potential peers with more higher compensated CEOs than for firms with lower compensated CEOs (i.e., the expected interaction effect is positive).

H4b: The effect of popularity on removing an existing peer will be larger for potential peers with lower compensated peers than for firms with higher compensated CEOs (i.e., the expcted interaction effect is negative).

To summarize, while the aggregate pattern of compensation peer group bias by itself raises serious questions for the hidden talent hypothesis, we focus in this paper on the microlevel dynamics of peer groups to construct an alternative test for the presence of bias in compensation peer groups. We first use our new data to re-estimate compensation peer group bias using methods (simulation and propensity score matching) that have previously been used to estimate the peer pay effect. Then, building on the intuition that stable CEO tenure at the peer firm and at the focal firm implies that talent has remained stable for both firms, we argue that the net effect of peer compensation (that is, the effect after controlling talent changes) in the addition or removal of peer firms should be zero. We examine this argument by analyzing the characteristics of the added and dropped firms vis-a-vis the characterustics of a set of counterfactual additions or removals. We then analyze the use of popularity as a mechanism to increase the efficacy of impression management. As we will show, our evidence supports the conclusion that certain firms and CEOs seek to maintain bias in their peer groups beyond that which can be accounted for by corporate size, industry, corporate performance, or the past accomplishments of the CEO. 


\section{Data and Sample Selection}

Our dataset is directly based on the written reports that firms are required to file annually with the Securities and Exchange Commission (SEC). In these reports, firms disclose a list of peer firms used in the process of setting CEO compensation. Because missing data can bias calculations of the peer pay effect, it is important that data on compensation peers be as complete as possible. This means that we need data not just on all firms that select peers, but also data on all firms that are named - or that potentially could be named as peers of these firms. To ensure that the non-reporting peers can be identified, and to ensure that data are available on the compensation practices of both reporting firms and non-reporting peers, we draw on two universes of firms: (a) A historical listing of all firms that have reported to the SEC - a list that contains more than 500,000 entries ${ }^{8}$ - and (b) all firms in Morningstar's Executive Compensation database, including all firms that were acquired or have gone out of business since 2006 - this list contains more than 7,000 US entries.

Our starting point for identifying firms that name peers is the DEF $14 \mathrm{~A}$ or DEF $14 \mathrm{C}$ form filed with the SEC. These DEF 14 forms include a "Compensation Discussion and Analysis" section, where the firm provides a rationale for the compensation package they provide to the $\mathrm{CEO}$, and where they detail the various components of total executive compensation. This is also the section in which a firm names the peer firms it uses for benchmarking its executive compensation. We downloaded these forms for all firms in Morningstar's executive compensation database for the years 2007 to $2012 .{ }^{9}$ We then created a computer algorithm that identifies and extracts the peers from one of these two forms. We trained the algorithm on a dataset of 500 known peer groups reported for the 2011 fiscal year and collected by Equilar. The algorithm is able to distinguish between performance peers (not used in the CEO pay-setting process) and compensation peers, and it distinguishes between compensation peers used to set compensation for the CEO and compensation peer groups used to set compensation of other executives. After extracting the peers from the DEF 14 form, another algorithm matches the names of the reported firms to

\footnotetext{
${ }^{8}$ This list is available at $1 . u s a . g o v / 1 t c P n 8 D$

${ }^{9} \mathrm{DEF} 14 \mathrm{~s}$ are submitted and made publicly available at the end of the fiscal year. Many fiscal years end during the spring - typically referred to as proxy season - so our data covers fiscal years 2007 to 2011.
} 
the SEC database of 500,000+ firms. Since firm names are sometimes misspelled or abbreviations are sometimes used, the algorithm includes a fuzzy matching procedure to match the extracted firm names to a name in the SEC universe. The algorithm achieved a very high sensitivity and specificity - $98 \%$ and $97 \%$, respectively - when applied to a sample of 500 firms that had been manually coded by Equilar. ${ }^{10}$ Once this process is done, each firm is assigned its Central Index Key (CIK) which can be used to match the peer data to the other datasets that we employ in our analyses.

Our algorithm extracted data on the peers of 1,500+ unique firms that reported in at least three consecutive years and included at least 5 peer firms in their peer group. We then matched the peer data with financial data from the Compustat database, with compensation data from Morningstar and Execucomp ${ }^{11}$, and with data from Dow Jones and we removed those observations for which more than one peer firm had no financial data or compensation data. The resulting data set contains the peers of 1,443 unique firms that reported in at least three consecutive years. In Table 1 we report descriptive statistics on the peer groups per year. The table shows that the average number of peers in a peer group is rather stable between 2007 and 2011. Table 1 also shows that between $71 \%$ and $75 \%$ of all disclosing firms update their peer group from year to year by adding or removing peers. The final two statistics show that in each year, the average disclosing firm adds a number of firms that is equal to $15 \%$ to $19 \%$ percent of its peer group in the previous year and removes between $16 \%$ and $19 \%$ of its peers in a given year. This dynamic information about peer group composition is the basis for the longitudinal analyses aimed at understanding persistence in peer selection patterns.

[Table 1 about here.]

The data that we have collected represents a much larger sample and includes more years of data than prior studies on named peers and CEO compensation. For example, Bizjak, Lemmon, and Nguyen (2011) collected data on 707 firms reporting in 2007, while

\footnotetext{
${ }^{10}$ Sensitivity captures the proportion of positives which are correctly identified as such (alternative: type I error) and specificity captures the proportion of negatives which are correctly identified as such (alternative: type II error).

${ }^{11}$ Morningstar Executive Insight provides superior coverage (more than 7,000 firms) as compared with Execucomp, which only contains data on firms in the S\&P 1500, and coverage is crucial for accurate estimation of the compensation distribution of named or "natural" peers.
} 
Faulkender and Yang (2013) employ a sample of 763 firms that have reported in at least one of four years resulting in a dataset of 2,066 firm-years (the average firm is represented in 2.7 years). This sample is slightly larger than the 657 firms that were included in the sample used in their 2010 paper (Faulkender and Yang, 2010). Albuquerque et al. (2013) employs the largest database. The authors collect data from 3 years $(2007,2008,2009)$ and start out with 1,273 unique firms that select peers and 3,158 firm-year observations (this is an average of 2.5 years of data for the average firm). Throughout their analyses the number of firm-years in the sample drops to 2,158 due to missing data issues. Our database is almost twice as large (in terms of numbers of firms) as the samples used in Bizjak, Lemmon, and Nguyen (2011), Faulkender and Yang (2010), and Faulkender and Yang (2013) and it includes more firms than Albuquerque et al. (2013) while being more restrictive on which firms to include (only those firms that reported in at least 3 years).

The only comparable source of data to ours on compensation peers is a commercial data product (Equilar Insight) available from Equilar. Our data have two important advantages compared with the Equilar data product. First, our data go back to the start of the reporting requirement in 2006 whereas Equilar data begin in 2008. Second, the cost of licensing the Equilar data is prohibitively high for the pocketbooks of academic researchers. Comparisons of summary statistics from our data and from the Equilar data for the S\&P 1500 firms shows a very close correspondence. ${ }^{12}$

\section{Peer Groups as Benchmarks and the Peer Pay Effect}

We first probe how the compensation of CEOs of the firms that select peers compare visa-vis the compensation of the CEOs of selected peer firms, and we explain and report our estimates for the compensation bias in named peer groups. In the left panel of Figure 2 we plot the yearly averages and standard errors of the percentiles in the peer group compensation distribution at which the focal CEO is compensated. The graph shows that there is very little change from year to year and that the average point in the distribution is typically the $45^{t h}$ percentile. In the right panel of Figure 2 we have plotted the distribution of percentiles for all firms that reported for fiscal year 2011. The mean lies at the $45^{\text {th }}$ per-

\footnotetext{
${ }^{12}$ The table of comparative statistics is available from the authors.
} 
centile while the median is slightly lower at the $43^{\text {rd }}$ percentile.

[Figure 2 about here.]

The peer pay effect ${ }^{13}$ is the difference at some point in the distribution (e.g., the median or the mean) between the compensation of named peers and of peers obtained through an alternative or counterfactual selection based on objective characteristics of the focal company and of potential peer companies. We compute the peer pay effect in five ways, four of which are based on simulations, while the fifth method uses propensity score matching. The first method uses a simulation approach and matches each firm that selected peers to an alternative peer group of the same size as the named peer group. Peers are matched to the focal firm based on the similarity in the three most frequently named selection criteria: Industry Classification, Revenue, and Market Capitalization. ${ }^{14}$ To operationalize the industry variable, we use the Global Industry Classification Standard (GICS) developed by MSCI and Standard \& Poor's (S\&P). GICS has four levels organized from inclusive to detailed in a hierarchy: "sector", "group", "industry", "subindustry." We operationalize revenue and market capitalization using data from Compustat. For both revenue and market capitalization, we set the lower boundary to $50 \%$ of the selecting firm's values and the upper boundary to $200 \%$ of the selecting firm's values. We start with the most detailed industry classification, and use the revenue and market capitalization boundaries rigidly. Within these limits we make 500 draws without replacement in which we randomly select as many counterfactual peers as there are firms in the named peer group. If the simulation population does not yield at least as many firms as there are firms in the named peer group we move one level up in the industry classification hierarchy. We repeat this process until there are at least as many peers in the population of potential peers as there are peers in the named peer group. For each of the 500 random draws from the population we compute the median pay in the simulated peer group.

The second method replicates the first method but includes as an additional selection criterion a variable that measures the "managerial talent" of the CEO. In addition

\footnotetext{
${ }^{13}$ Throughout this paper we use the terms "peer pay effect" and "compensation bias" interchangeably. Both terms refer to the same concept.

${ }^{14}$ See the yearly Equilar compensation report for more details on the selection criteria (http://www.equilar.com/corporate-governance/2012-reports).
} 
to the size and performance measures of Albuquerque et al. (2013), scholars have used several proxies, all of which have limitations. Perhaps the most frequently used measure of managerial talent is the fixed effect for a manager that is estimated from a wage equation (Bertrand and Schoar, 2003; Graham et al., 2011). A major problem of this approach, however, is that by using a wage equation with compensation as the dependent variable, one is explicitly assuming that the variance in compensation that is not explained by the model captures talent - an assumption that is obviously problematic. Recently, Demerjian et al. (2012) proposed a measure based on data envelopment analysis (DEA) to assess how successful CEOs are in converting inputs into outputs. Their measure is essentially an estimate of a manager's contribution to contemporary and past firm efficiency, net of a set of firm characteristics that would also generally be related to firm efficiency. Because the authors find that the measure behaves very well as a predictor of future returns, we used their method as the operationalization of CEO talent. The managerial ability measure is normally distributed with a mean of -0.004 , a median of -0.013 , and an interquartile range of 0.169. The values of the variable range from -0.415 to 0.557 . Since firms do not explicitly mention the boundaries within which they search for talented CEOs, we set the boundaries at the talent scores located five percentage points below and five percentage points above the talent score of the focal CEO in the CEO talent distribution.

The third and the fourth methods are similar to the first and the second respectively, but rather than allowing firms to break only out of the industry criterion, we randomly select a criterion (size and industry for method 3, and size, industry, and talent for method 4) and loosen the boundaries of that criterion when the potential peer population would otherwise be too small. Finally, the fifth method for computing the peer pay effect replicates the analyses conducted by Faulkender and Yang $(2010,2013)$ and Albuquerque et al. (2013). They use a form of propensity score matching to construct counterfactual peer groups. Essentially, they create a risk set of potential peers for each selecting firm, and they include variables (using dummy variables) that capture the similarity between the selecting firm and the peer at risk of being selected. The data for each selecting firm is then stacked and a Probit regression is run to compute the predicted probability of being selected. The predicted probability of each selected peer (note that these probabilities differ 
across the set of named peers) is then used to match (using nearest neighbor matching) each named peer and a potential peer from the risk set. They then computed the difference in compensation between the selected and the matched peer, and calculated the median of the differences. This median constitutes the peer pay effect. ${ }^{15}$ For this analysis, we used the same predictors as Faulkender and Yang (2010, 2013) and Albuquerque et al. (2013), each of which is listed and defined in Table A1 in Appendix A. ${ }^{16}$

In appendix B we show the distribution of the median peer pay effect using the matching method of Faulkender and Yang $(2010,2013)$ and Albuquerque et al. (2013). Our main reasons for using the simulation method (and specifically, method 1) rather than the propensity score method (method 5 above) are threefold: (a) the propensity score method finds counterfactual peers based on characteristics of the named peers rather than of the focal firm, (b) since the method uses mainly dummy variables, some named peers are very different from their counterfactual peers, ${ }^{17}$ and (c) the propensity score method does not allow one to compute confidence intervals around the estimates of the peer pay effect. ${ }^{18}$

\section{[Figure 3 about here.}

The mean peer pay effects using each of the first four methods are shown in Figure 3, where the effect is represented both in dollar and in percentage terms. Throughout this pa-

\footnotetext{
${ }^{15}$ For the computation of the peer pay effect, it is important to pay attention to the temporal trajectory of the peer selection process. DEF $14 \mathrm{~s}$ are submitted and become publicly available at the end of the fiscal year because only then will the compensation of executives be known. The peer groups however are determined prior to the fiscal year. The precise dates at which peer groups are decided upon are not known, and informal discussions with several compensation consultants revealed that the date at which the compensation committee meets may change from year to year and the interval in between the meeting and the start of the fiscal year varies by firm. As a result, it is impossible to pin down the exact information used by the compensation committee to form the peer group. The analyses in this paper where the compensation of the focal CEO and its peer CEOs are compared build on data in the year prior to the fiscal year for which the peer group is reported. However, since peer groups are only disclosed at the end of the fiscal year, it is likely that investors and shareholders will use more recent data to assess the composition of the peer group. In the paper we report results based on comparisons with a one year lag. We also replicated our analyses using comparisons of a two year lag and no lag. The results from these alternative analyses are qualitatively, and are available from the authors upon request.

${ }^{16}$ All variables from this analysis, and all variables of subsequent analyses will be listed in Table A1. The order of the list follows the order in which the variables are introduced.

${ }^{17}$ For example, in one instance BJs Restaurants Inc., a named peer of Famous Daves of America Inc. with a revenue of $\$ 316$ million, is matched to MGM Resorts International which has 24 times as much revenue $\$ 7.7$ billion

${ }^{18}$ We must also note that we replicated the PSM approach by including the ability measure of Demerjian et al. (2012). The effect of managerial talent on the likelihood of being selected is positive and significant. Yet, the effect of peer compensation on the likelihood of being selected remains positive and significant, indicating that even the PSM method produces results that are inconsistent with the "hidden talent argument".
} 
per we will use the results from the first method as our measure of the peer pay effect. It is the most conservative measure and pairwise comparisons show that it is nearly indistinguishable from the measure that includes talent. Figure 3 shows that the mean peer pay effect is substantial using all four simulation methods, varying from over $25 \%$ to nearly $40 \%$ of total compensation, depending on the particular percentile of peer group bias that we focus on. It is especially noteworthy that the peer pay effect is still readily visible even when we match CEOs to potential peers using a talent measure as well as measures of size and industry. In Figure 4, we plot the distribution of the median peer pay effect using the simulation method from method 1. It shows that the majority of firms use bias in the pay setting process, and specifically create peer groups with positive bias at the median of their named compensation peer group distribution.

[Figure 4 about here.]

Although peers are selected based on criteria named by the selecting firm, distributional properties of the sample could result in the selection of peers that are smaller or larger than the focal firm. For example, one expects the simulated peers for firms in the right tail of the size distribution to be smaller than the focal firm. ${ }^{19}$ We find it is indeed the case that the median revenues in the simulated peer group are lower than those of the focal firm at the top of the distribution (by $4.5 \%$ in decile $8,9 \%$ in decile 9 , and $19 \%$ in the top decile). In the analyses below where the peer pay effect is the dependent variable, we take this pattern into account by controlling for firm size (i.e., market cap, revenues) in the regressions. Analyses that control for deciles of firm revenue or that limit the sample to the focal firms in the bottom $80 \%$ of the revenue distribution produce similar results to the ones presented here (they are available from the authors upon request).

Before we turn to the analyses of peer group dynamics, we examine the variation in the peer pay effect between firms. In Figure 5, we present scatter plots of two variables of interest - pay percentile and the percentage bias - and we fit a Loess curve to assess the pattern in the bivariate relation between them. The left panels assess the relationship between

\footnotetext{
${ }^{19}$ This is less the case for firms in the left tail of the size distribution, because while the limit in the right tail is a natural limit (firm size has a natural maximum), the left tail limit - imposed by the firm size threshold beyond which reporting peers is mandatory - is circumvented by extending our sample beyond firms that select. As we have already mentioned our analyses are based on a broad sample of firms that select and could be selected.
} 
peer group bias and the percentile in the named peer group at which the focal CEO is paid. The right panels assess the relationship between peer group bias and the percentile in the natural peer group at which the focal CEO is paid. The graphs clearly show a negative relationship between the peer group bias and the pay percentile in the named peer group, and a positive relationship between those two variables using the natural peer group. Focusing on the named peer group, the bivariate analysis indicates that the bias at the 25th percentile is $45 \%$ while the bias at the 75 th percentile is $11 \%{ }^{20}$ In other words, CEOs who are highly paid relative to their natural peer group generally have greater bias in their named peer groups. Higher levels of bias in a peer group tend to push a CEO's compensation towards the left side of the distribution of his named peer group. As we show below, these results apply even when natural peer groups take account of the CEO talent measure developed by Demerjian et al. (2012).

[Figure 5 about here.]

We further investigate the relationship between CEO pay and peer group bias by estimating six regression models in which we specify the compensation bias as a function of a set of predictor variables including the percentile location in the natural and the named peer group at which the focal CEO is compensated. The dependent variable, "Peer Pay Effect" refers to the difference in compensation at the median in the named versus the simulated peer group. "Pay Percentile Named" and "Pay Percentile Natural" indicate the percentile in the named and simulated peer group respectively at which the focal CEO is compensated. Market Capitalization, Revenue, ROA, 1 year TSR, Leverage, and Market-2book ratio are all extracted from the Compustat dataset (see Table B1 of Appendix B for precise definitions of these variables). The correlation matrix for the variables included in the regression analysis is presented in Table 2, while the six regression models that we fitted are presented in Table 3. The correlation matrix indicates that market capitalization and revenue are highly correlated $(0.66, \mathrm{p}<0.05)$, but these variables function primarily as control variables in these equations and so precision in the estimation of their coefficients is not a central concern in this analysis.

[Table 2 about here.]

\footnotetext{
${ }^{20}$ These estimates both have a standard error of $1.6 \%$.
} 
The first three regression models are pooled OLS models while the second set of three models includes OLS firm-fixed-effects regression models. Both sets of models include the firm performance variables that might reasonably be assumed to predict CEO compensation. Models 3 and 6 show that the effect of pay percentile in the natural peer group (Pay pct. natural) is positive and statistically significant, net of market capitalization, revenue, return on assets, total shareholder return, leverage, and book value. In other words, CEOs who are paid well, controlling for their performance, tend to have more strongly biased compensation peer groups. Meanwhile, models 2 and 6 show that the pay percentile in the named peer group (Pay pct. named) is negatively related to the peer pay effect. These findings are consistent with hypothesis $1 \mathrm{a}$ and hypothesis $1 \mathrm{~b}$; if firms want to compensate their CEO well relative to the natural peer group, they have a tendency to introduce bias in the naming of peer groups. Whether the bias "causes" the high pay or whether the intent to pay especially well motivates the use of bias cannot directly be answered by this analysis. It does appear true, however, that firms frequently disguise how well their CEOs are paid relative to a neutrally selected peer group by inflating the named peer group with highly paid CEOs from larger firms that push the focal CEO pay to the left side of the named peer group compensation distribution.

[Table 3 about here.]

To further probe these findings, we focus on the managerial ability variable. The variable is negative and significant in all pooled OLS models and negative and significant in two of the three fixed effects models. ${ }^{21}$ This suggests that CEOs with high levels of managerial ability have lower levels of bias in their named peer groups. This pattern is consistent with the presumption that it is easier for a firm to argue for the legitimacy of paying a CEO further to the right in the benchmark distribution when it can justify this pay in terms of the managerial attributes that predict pay in the Demerjian et al. (2012) construct. When a justification in these terms is lacking, there is an increased tendency for the firm to bias the named compensation peer group and thereby make his pay seem lower relative to the benchmark than would be the case if less biased or if a neutrally selected

\footnotetext{
${ }^{21}$ Remember, firm fixed effects models builds on variation within each firm and since Managerial Ability is a very stable variable, the variation comes mainly from CEO mobility.
} 
"natural" peer group were used instead.

To better understand the role of managerial ability in the pay setting process, we plotted in Figure 6 how managerial ability relates to the pay percentile natural, pay percentile named, and peer pay effect variables. The lines in the graphs are the bivariate linear regression lines. The coefficients of the slopes in panel 1 and 3 are both negative and significant at the 0.01 level, while slope of the regression line in panel 2 is essentially zero. The graphs show a clear pattern: talented CEOs are typically compensated at the $50^{\text {th }}$ percentile of the compensation distribution of their natural peer group and the positive bias in their named peer group is much lower than the bias used by relatively untalented CEOs. Moreover, talented CEOs are compensated at the same percentile of the named peer group as their less talented counterparts, but since they use less bias in the named peer group, they are right at the 50th percentile of the natural peer group. Less talented CEOs are paid at much higher percentiles of the natural peer group. These findings indicate that CEOs with relatively little talent are the main source of a trend of overly generous pay. In a sense these findings imply a masked version of the "Lake Wobegon" effect (DiPrete et al., 2010): no CEOs are below average but the "above average" character of CEO pay is differently disguised. CEO's who are above average in talent are more likely to be presented as truly above average in pay. The pay of lesser talented CEOs may also be above average in

fact, but it is presented to the shareholders as if it is appropriately or even inappropriately low relative to the asserted benchmark distribution.

\section{[Figure 6 about here.]}

\section{Peer Group Dynamics}

Next we examine the dynamics of peer group composition. It is an empirical fact that firms regularly make changes to the composition of their peer groups (see Table 1). This raises two obvious questions. First, given that there are normative criteria for selecting peers, are firms using these same criteria when they change their peer groups? Second, if firms use additional criteria besides the normative ones, then what additional criteria are they using? In particular, are they also paying attention to changes in the compensation of the 
CEOs of current peers and of potential peers in making decisions about changes to their compensation peer groups?

The first analysis presented here is intended to determine the characteristics of firms that are removed from the compensation peer group of a focal firm. We model which firms are removed from the peer group using conditional logistic regression. We construct the set of firms that are at risk of being removed simply as the peers that were in the peer group in year $t$. Peers that were removed from the peer group in year $t+1$ are then coded as "removed (1)" while the other peers are coded as "remaining (0)".

The second set of regression models describes the process by which peers are added to the peer group. The risk set for the analysis in which the addition of peers is the event of interest is defined using another strategy. For this analysis, we matched every added peer to ten firms that were randomly selected from a sample of firms that are in the same industry and same size category (50\%-200\%) - both in market capitalization and revenue - as the peer. These firms represent counterfactual peers for the observed selection of an added peer. The use of these criteria is in line with prior studies (Pittinsky and DiPrete, 2013; Faulkender and Yang, 2010, 2013; Albuquerque et al., 2013).

\section{Results}

Table 4 first tabulates some descriptive statistics on the variables used in the analysis. In model 1 of Table 5, based on a universe that comprises all firms that removed at least one peer, we specify the removal of a peer as a function of peer characteristics including revenue, market capitalization, same industry, changed CEO, and logged peer compensation. The dummy variable "same industry" is equal to 1 if the firm and the potential firm are in the same GICS industry. Another dummy variable, "changed CEO", is equal to 1 if the potential peer firm has changed it's CEO (see Table A1 in Appendix A for operationalizations and data sources for these variables). In model 2 and 3 we add a "peer popularity" variable which is measured as the percentile rank of the number of firms in the prior year that selected a specific peer. We test for non-linearity in the peer popularity variable by including squared and cubed terms. To assess whether the findings in models 1 to 3 are robust when accounting for managerial talent, we include the managerial ability variable intro- 
duced earlier in the paper. Because managerial talent cannot be computed for every observation, the sample size drops by about $23 \%$ when including the talent variable. ${ }^{22}$ Finally, in models 5 and 6 we include two interactions: one between peer popularity and $\log ($ peer compensation) and the other between CEO change and $\log$ (peer compensation). We use a conditional logistic regression to asses whether characteristics of the peer firm predict the removal from the peer group.

[Table 4 about here.]

[Table 5 about here.]

Model 1 in Table 5 indicates that the size of the peer, as measured by revenue, is positively related to removal from the peer group. Market capitalization, however, is negatively related to a firm's probability of being removed from the peer group. Table 4 shows that the two predictor variables are highly correlated and the coefficients of their correlation with the outcome variable is negative in both cases. One should therefore not interpret the positive and significant coefficient for the revenue variable as evidence that peers with high revenue are more likely to be removed from a peer group. Model 1 also indicates that peers are less likely to be removed when they are active in the same industry as the selecting peer. This finding is consistent with prior findings that indicate that firms named as peers are more likely to be active in the same industry as the focal firm. Firms are more likely to remove a firm from the peer group if the CEO of that peer changed. Apparently, the removal of a peer from the peer group is not just a function of the characteristics of that firm but also of the characteristics of its management. The coefficient for $\log$ (peer compensation) is negative and statistically significant indicating that firms that firms that employ highly compensated CEOs are less likely to be removed from the peer group than are firms that compensate their $\mathrm{CEO}$ at moderate levels.

Model 2 includes the peer popularity variable. If firms that employ well compensated CEOs are also popular peers (an assumption that is confirmed by the strong positive correlation shown in Table 4), the inclusion of a peer popularity variable could reveal an alternative explanation for the negative effect of $\log$ (peer compensation) on removal from

\footnotetext{
${ }^{22}$ All models in Table 5 have also been estimated with the managerial ability variable included. The results are similar to the results shown in this paper. The table with alternative specifications are available from the authors.
} 
the peer group presented in model 1 . The results from model 2 are consistent with this alternative explanation. The coefficient of $\log$ (peer compensation) is no longer significantly different from zero. However, the coefficient for peer popularity is negative and significant indicating that popular peers are less likely to be removed from the peer group than unpopular peers. Model 3 further probes this result by estimating non-linearity in this effect. Although the squared term is positive and the cubed term is negative, suggesting a nonmonotonic effect of peer popularity on the probability of removal, the coefficients are not significant. Model 4, presents the results for a specification similar to model 3, but we add the managerial talent measure. The coefficient is negative and significant; this implies that peers with more talented CEOs are less likely to be removed from the peer group, net of the other factors in the model including peer popularity. Given that managerial talent predicts future performance, perhaps these CEOs are viewed as especially valuable as comparison points in the belief that they are likely to experience faster than average compensation gains.

The findings from model 1 to model 3 give rise to the question of whether the effect of peer popularity is similar across various levels of $\log$ (peer compensation). In model 5 we include an interaction between peer popularity and $\log$ (peer compensation). The coefficient for the interaction term is statistically significant and positive, while the coefficients for peer popularity and $\log$ (peer compensation) are negative and significant. Jointly, these terms can be interpreted as follows: for low levels of peer compensation, popularity has a stronger effect on the probability of removal than at high levels of peer CEO compensation. This accords with the prediction of hypothesis $4 \mathrm{~b}$. To illustrate the details of the interaction, Figure 7 shows how peer popularity moderates the effect of $\log$ (peer compensation) on the likelihood of being removed. The y-axis of the graph shows the relative risk of removal of a given observation as compared to the stratum (peer group) average. The regression line for popular peers lies below a relative risk of 1 meaning that highly popular peers are always less likely to be removed from the peer group. Although this effect is positively moderated by $\log$ (peer compensation), the difference between a highly compensated peer CEO and those who receive relatively little compensation is minimal. For unpopular peers, the difference the relative risk of removal between highly compensated peer 
CEOs and CEOs receiving much less generous pay packages is very large. To put it another way, the effect of popularity is clearly larger at lower peer CEO compensation levels than at higher levels.

Finally, in model 6 we include an interaction between CEO change and log(peer compensation). The inclusion of this interaction allows us to assess whether the effect of log(compensation) can be accounted for by the change of CEO in the firms in the peer group. The coefficient for the interaction term is statistically significant and positive, while the coefficients for CEO change and $\log$ (peer compensation) are negative and the coefficients for CEO change is significant. The coefficients for these three coefficients are jointly significant. Although at high levels of $\log$ (peer compensation) the effect on removal from the peer group is significantly different between peers that had a CEO change and peers that had not, this difference is minimal.

\section{[Figure 7 about here.]}

Next, we address the factors linked to the addition of a new peer. We construct a risk set for the process of adding peers that comprises the added company and ten other companies selected at random from the same industry that are similar in market capitalization and similar in revenue to the added peer, using a similar methodology to that we employed for the peer pay effect simulations. If the generation of counterfactual firms, based on the industry, market capitalization, and revenue criteria, does not yield 10 firms, we randomly select a criterion for which we widen the boundaries. In Table 6 we present descriptive statistics and correlations for the risk set data. Similar to the models in Table 5, we then specify a conditional logistic regression model for the probability that a potential peer firm is added to the peer group as a function of revenue, market capitalization, changed CEO, peer popularity, and managerial ability. The results from these regressions are presented in Table 7.

Model 1 in Table 7 shows that peers are more likely to be added to the peer group if market capitalization and revenue are high. The model also shows that peers that employ well compensated CEOs are more likely to be added to peer groups that they are not already members of. In model 2 we test whether this finding can be accounted for by the popularity of the peer. The model shows that popular firms - i.e., firms that are relatively 
frequently the members of peer groups in the previous year - are more likely to be added to peer groups that they are not already members of, but that the coefficient of $\log$ (peer compensation) remains positive and significant. In model 3 we test for non-linearity in the effect of peer popularity. The squared term is negative and significant, while the cubed term is positive and significant. These results suggest that the effect of an increase in popularity becomes less pronounced as popularity increases, but that the effect for exceptionally popular peers is even stronger.

Model 4 tests whether the omission of a managerial ability variable causes us to misspecify the relation between the dependent and independent variables. ${ }^{23}$ The results show that it does not. The point estimates and confidence intervals for the independent variables are qualitatively similar to the estimates in model 3. Moreover, the effect of managerial ability is positive and significant. Firms favor the addition of firms as peers that have talented CEOs. Talent, compensation, and popularity all appear to affect the process by which firms update their list of peers.

In model 5 we include an interaction between the logged CEO compensation of the candidate peer and peer popularity. Consistent with hypothesis 4a, the coefficient estimates indicate that the effect of popularity on the addition of a potential peer is stronger for more highly compensated potential peer CEOs than for lower compensated peer CEOS. Figure 8 provides the details for the relation. While the relative risk for popular peers who pay their CEOs in the left tail of the compensation distribution is essentially 1 , the relative risk increases to about 2 if the popular peer is well compensated. This result is consistent with the idea that popularity serves as a mechanism that legitimizes the inclusion of well compensated CEOs in the peer group.

Finally, in model 5 we add an interaction effect between $\log$ (peer compensation) and CEO change. Similar to the models presented in Table 5, this interaction provides a direct test for hypothesis 2 . The signs of the coefficients for the interaction and its main effects demonstrate that although the effect of $\log$ (peer compensation) is less pronounced when the CEO of the peer has changed, the effect is minimal.

[Table 6 about here.]

\footnotetext{
${ }^{23}$ Again, please note that because the managerial ability variable is not available for all firms in the sample, the number of observations drops significantly.
} 
[Table 7 about here.]

[Figure 8 about here.]

\section{Discussion and Conclusion}

The literature on executive compensation remains divided between research findings of managerial power and self-serving behavior on the one hand and market returns for performance on the other. Proponents of the managerial power argument have pointed to the failure of firms to index stock options to avoid rewarding CEOs for general stock market rises unrelated to own performance, or the backdating of stock options as evidence for managerial power explanations (Bebchuk and Fried, 2004; Bebchuk et al., 2006). Proponents of the "pay for performance" explanation have argued that executive pay has been bid up by the rising size of firms coupled with the argument that CEO talent is worth more in large firms (Gabaix and Landier, 2008; Gabaix et al., 2014). They also point to the generally positive correlation between firm performance and executive pay and the increased use of "pay at risk" forms of compensation. This increasing tendency towards "pay at risk" structures has been evidenced by the increasing use of especially restricted stock grants, corporate boards that exercise more monitoring power over CEOs - e.g., they are more likely to fire the CEO if the company is performing poorly (Adams et al., 2010) -, and the overwhelming tendency for CEO compensation to be approved in stockholder "say on pay" votes. These trends are interpreted by some scholars as evidence that CEO pay arises out of optimal contracts rather than out of weak corporate governance and excessive executive power over the terms of executive compensation (Conyon, 2014).

Whether performance and pay are positively correlated, or whether poor performance is more likely than good performance to lead to board action to replace the CEO cannot, by itself, provide evidence against the argument that CEOs are collecting sizable rents made possible by an inadequate alignment of board actions and shareholder interests. Our approach in this paper has been to look for more direct forms of evidence of behavior that cannot readily be explained in terms of market compensation models, of which the selection of biased compensation peer groups would seem to be an excellent example. Our re- 
sults suggest that the evidence for bias in the selection of these peer groups would appear to be rather strong.

Earlier in the paper, we discussed arguments by Albuquerque et al. (2013) that apparently biased peer groups may be explainable as a consequence of the "hidden talent" of these CEOs. We were critical of the interpretation of their results because the variables they used to operationalize "hidden talent" could instead be interpreted as operationalizations of rent seeking on the part of the CEOs in question. The results presented in this paper are difficult to reconcile with any version of the "hidden talent" argument. Talent may well matter to the selection of peer groups, but it does not explain the peer group pay effect.

Indeed, our results suggest a process that is quite different from the "bias as a reward for talent" story in Albuquerque et al. (2013). Peer group bias is generally smaller in firms where managerial ability is high. The bias grows in firms with CEOs whose managerial talent scores are relatively low. Far from being a reward for talent, peer group bias appears to be used as a form of impression management. When there is direct evidence of the quality of the focal CEO, the firm appears to be more comfortable in proclaiming their boss to be "above average" in compensation relative to an asserted benchmark distribution. But when the evidence suggests that the CEO is "below average" in ability, firms seem to have a tendency to hide the true place in the benchmark distribution at which he is paid by adding upward bias to the benchmark distribution to make it appear that their $\mathrm{CEO}$ is further to the left of the benchmark distribution in his pay than is actually the case. This behavior would seem intended to create the - arguably misleading - impression that their CEO is not overpaid, and maybe is even underpaid, compared with the relevant market. Finally, our analyses on the dynamics of peer groups suggest that since talent is a durable characteristic of CEOs and since our findings hold for both firms that had peers with changing CEOs and peers with non-changing CEOs, the tendency to select peers with highly paid CEOs cannot be accounted for by an omitted variable that captures CEO talent.

Further evidence on the biasing of peer groups comes from attention to peer group dynamics. Here we find that non-normative criteria such as peer popularity or the compensation of peer CEOs play a role in the removal and addition of peers. We find a general 
pattern in the process of adding peers that favors popular peers and especially so when the potential peer to be added has a well-paid CEO and therefore is more likely to be an instance of bias-enhancement of the CEO's compensation benchmark distribution. Moreover, our results suggest that firms mask the removal of firms with relatively low-compensated CEOs from their peer group by especially targeting the low-popularity poorly compensated CEO firms. This targeting potentially adds legitimacy to the choice of firms to remove and arguably masks the fact that the choice to remove a firm with a low-compensated CEO from the peer group enhances the bias of the named peer group. In short, our findings are consistent with the argument that reliance on a non-standard but seemingly normative popularity criterion legitimizes otherwise deviant behavior.

Finally, we also find that firms generally pay attention to the managerial ability of peer and candidate peer CEOs. They are less likely to remove highly talented CEOs from their peer group and they are more likely to favor highly talented CEOs when choosing among firms to add to the peer group. The fact that Demerjian et al. (2012) has found this talent measure to predict future performance suggests that the favoring of talented CEOs may be a self-serving strategy; these CEOs are arguably likely to have above average growth in compensation, which pushes up the benchmark distribution and thereby justifies higher pay for the focal CEO.

Collectively, the evidence presented in this paper points to a favoring of firms as peers that provide legitimacy for the peer group and that tend to push the focal CEO to the left of his benchmark distribution, thereby creating the impression that he is not overpaid and indeed may be underpaid. Impression management appears to play a large a role in the construction of benchmarks for the compensation of a firm's chief executive. 


\section{References}

Adams, R. B., B. E. Hermalin, and M. S. Weisbach (2010). The role of boards of directors in corporate governance: A conceptual framework and survey. Journal of Economic Literature 48(1), 58-107.

Albuquerque, A. M., G. De Franco, and R. S. Verdi (2013). Peer choice in ceo compensation. Journal of Financial Economics 108(1), 160-181.

Bakija, J., A. Cole, and B. Heim (2010). Jobs and income growth of top earners and the causes of changing income inequality: Evidence from us tax return data. Department of Economics Working Papers.

Barkema, H. G. and J. M. Pennings (1998). Top management pay: Impact of overt and covert power. Organization Studies 19(6), 975-1003.

Baron, D. P. (2001). Private politics, corporate social responsibility, and integrated strategy. Journal of Economics and Management Strategy 10(1), 7-45.

Bebchuk, L. and J. Fried (2005). Pay without performance: Overview of the issues. Journal of Corporation Law.

Bebchuk, L. A. and J. M. Fried (2004). Pay without performance : the unfulfilled promise of executive compensation. Cambridge, Mass.; London: Harvard University Press.

Bebchuk, L. A. and Y. Grinstein (2005). The growth of executive pay. Oxford Review of Economic Policy 21(2), 283-303.

Bebchuk, L. A., Y. Grinstein, and U. Peyer (2006). Lucky CEOs. Number 12771.

Bertrand, M. (2009). Ceos. Annu. Rev. Econ. 1(1), 121-150.

Bertrand, M. and A. Schoar (2003). Managing with style: The effect of managers on firm policies. The Quarterly Journal of Economics 118(4), 1169-1208.

Bizjak, J., M. Lemmon, and T. Nguyen (2011). Are all ceos above average? an empirical analysis of compensation peer groups and pay design. Journal of Financial Economics $100(3)$, 538-555. 
Bizjak, J. M., M. L. Lemmon, and L. Naveen (2008). Does the use of peer groups contribute to higher pay and less efficient compensation? Journal of Financial Economics 90(2), 152-168.

Chin, M. K., D. C. Hambrick, and L. K. Trevino (2013). Political ideologies of ceos: The influence of executives' values on corporate social responsibility. Administrative Science Quarterly 58(2), 197-232.

Conyon, M. J. (2014). Executive compensation and board governance in us firms. The Economic Journal 124(574), F60-F89.

Cook, F. W. (1981). The compensation director and the board's compensation committee. Compensation $\&$ Benefits Review 13(2), 37.

Demerjian, P., B. Lev, and S. McVay (2012). Quantifying managerial ability: A new measure and validity tests. Management Science 58(7), 1229-1248.

DiPrete, T. A., G. M. Eirich, and M. Pittinsky (2010). Compensation benchmarking, leapfrogs, and the surge in executive pay. American Journal of Sociology 115(6), 16711712.

Faulkender, M. and J. Yang (2010). Inside the black box: The role and composition of compensation peer groups. Journal of Financial Economics 96(2), 257-270.

Faulkender, M. and J. Yang (2013). Is disclosure an effective cleansing mechanism? the dynamics of compensation peer benchmarking. Review of Financial Studies 26(3), 806839.

Fernandes, N., M. A. Ferreira, P. Matos, and K. J. Murphy (2013). Are us ceos paid more? new international evidence. Review of Financial Studies 26(2), 323-367.

Frydman, C. and D. Jenter (2010). Ceo compensation. Annual Review of Financial Economics 2(1), 75-102.

Frydman, C. and R. E. Saks (2010). Executive compensation: a new view from a long-term perspective, 1936-2005. Review of Financial Studies 23(5), 2099. 
Gabaix, X. and A. Landier (2008). Why has ceo pay increased so much? The Quarterly Journal of Economics 123(1), 49-100.

Gabaix, X., A. Landier, and J. Sauvagnat (2014). Ceo pay and firm size: An update after the crisis. The Economic Journal 124(574), F40-F59.

Godfrey, P. C., C. B. Merrill, and J. M. Hansen (2009). The relationship between corporate social responsibility and shareholder value: an empirical test of the risk management hypothesis. Strategic Management Journal 30(4), 425-445.

Graham, J. R., S. Li, and J. Qiu (2011). Managerial attributes and executive compensation. Review of Financial Studies 25(1), 144-186.

Hambrick, D. C. (2007). Upper echelons theory: An update. Academy of management review 32(2), 334-343.

Hambrick, D. C. and P. A. Mason (1984). Upper echelons: The organization as a reflection of its top managers. Academy of management review 9(2), 193-206.

Harris, J. and P. Bromiley (2007). Incentives to cheat: The influence of executive compensation and firm performance on financial misrepresentation. Organization Science 18(3), $350-367$.

Hayes, R. M. and S. Schaefer (2009). Ceo pay and the lake wobegon effect. Journal of Financial Economics 94(2), 280-290.

Holmstrom, B. and S. N. Kaplan (2003). The state of u.s. corporate governance: What's right and what's wrong? Journal of Applied Corporate Finance 15(3), 8-20.

Huy, Q. N. (2002). Emotional balancing of organizational continuity and radical change: The contribution of middle managers. Administrative Science Quarterly 47(1), 31-69.

Larcker, D. F., A. L. McCall, and G. Ormazabal (2013). Outsourcing shareholder voting to proxy advisory firms. Rock Center for Corporate Governance at Stanford University Working Paper (119). 
Lie, E. (2005). On the timing of ceo stock option awards. Management Science 51(5), $802-812$.

McDonnell, M.-H. and B. King (2013). Keeping up appearances reputational threat and impression management after social movement boycotts. Administrative Science Quarterly 58(3), 387-419.

Murphy, K. J. (1999). Executive compensation. Handbook of labor economics 3, 2485-2563.

Piketty, T. (2014). Capital in the Twenty-First Century (First Edition edition ed.). Cambridge Massachusetts: Belknap Press.

Pittinsky, M. and T. A. DiPrete (2013). Peer group ties and executive compensation networks. Social Science Research 42(6), 1675-1692.

Reda, j. (2013). Say on pay: Changing how executives get paid. Financial Executive (September), 25-27.

Reda, J. F. and D. M. Schmidt (2014). The x factor: What lti measures drive corporate performance?

Roberts, D. R. (1956). A general theory of executive compensation based on statistically tested propositions. The Quarterly Journal of Economics 70(2), 270-294.

Schmidt, D. M. and J. F. Reda (2013). The end of golden parachutes? The Corporate Board (May/June).

Simon, H. A. (1957). The compensation of executives. Sociometry 20(1), 32-35.

Smith, E. B. (2014). The man pushing ceo pay to the stratosphere. The Fiscal Times April 29, 2014 .

Stark, D. (2009). The Sense of Dissonance: Accounts of Worth in Economic Life. Princeton University Press.

Stiglitz, J. E. (2012). The price of inequality: How today's divided society endangers our future. WW Norton \& Company. 
Wade, J., J. Porac, and T. Pollock (1997). Worth, words, and the justification of executive pay. Journal of Organizational Behavior.

Westphal, J. D., S. H. Park, M. L. McDonald, and M. L. A. Hayward (2012). Helping other ceos avoid bad press: Social exchange and impression management support among ceos in communications with journalists. Administrative Science Quarterly 57(2), 217-268.

Zajac, E. and J. Westphal (1995). Accounting for explanations of ceo compensation: Substance and symbolism. Administrative Science Quarterly.

Zott, C. and Q. N. Huy (2007). How entrepreneurs use symbolic management to acquire resources. Administrative Science Quarterly 52(1), 70-105.

Zuckerman, E. W. (2010). What if we had been in charge? the sociologist as builder of rational institutions. Research in the Sociology of Organizations 30, 359-378.

Zuckerman, E. W. (2012). Construction, concentration, and (dis) continuities in social valuations. Annual Review of Sociology 38, 223-245. 
Figure 1: CEO compensation and market capitalization in the S\&P 1500.
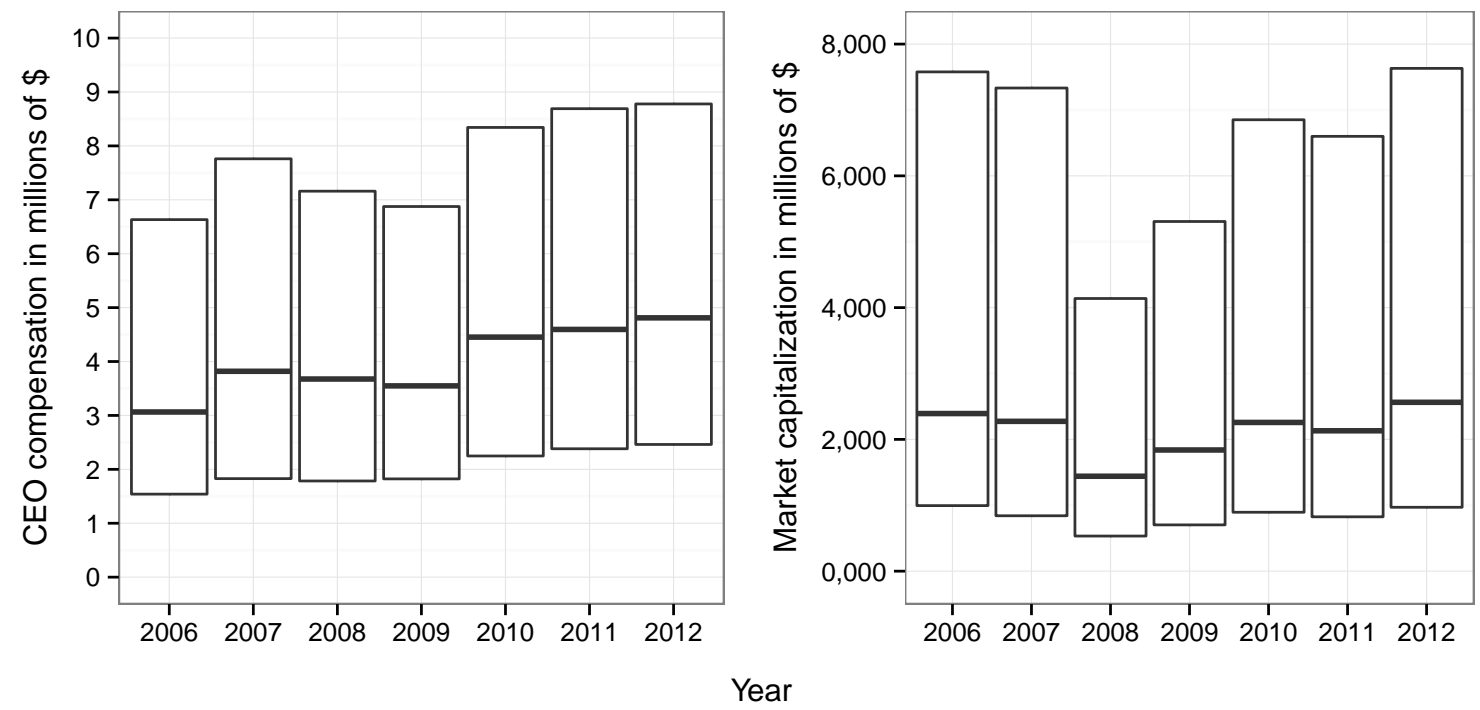

Note: The left panel shows box plots for CEO compensation and the right panel shows box plots for market capitalization. The lower and upper "hinges" represent the first and third quartiles respectively of the data distribution in that year. The whiskers are not shown in the graph because in both directions they extend beyond the upper and lower limit of the y-axis. 
Figure 2: Comparison of focal CEO and peer CEO compensation.
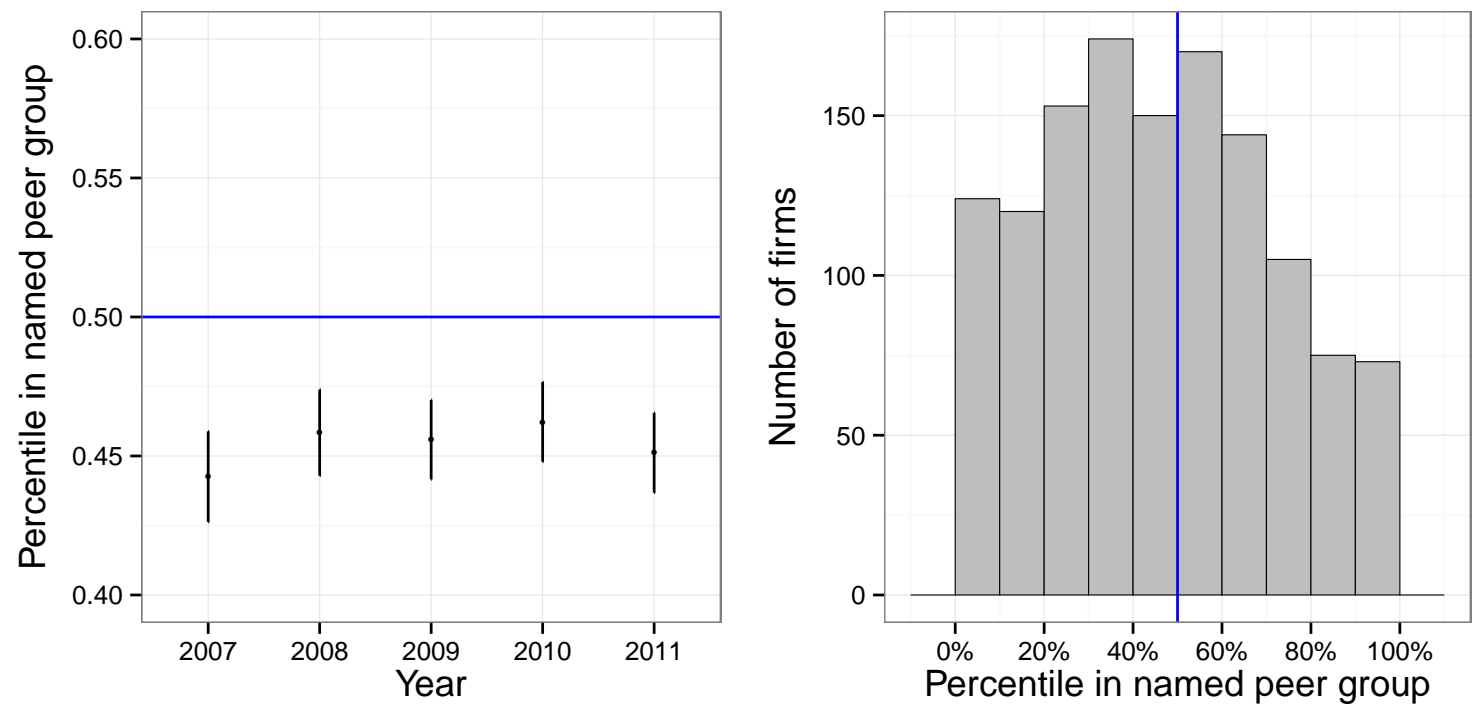

Note: In the right panel we have plotted the distribution for 2011. The distributions for the other years in our data are nearly identical. Blue lines indicate the $50^{t h}$ percentile. 
Figure 3: Comparison of bias estimate from 4 different simulation methods.
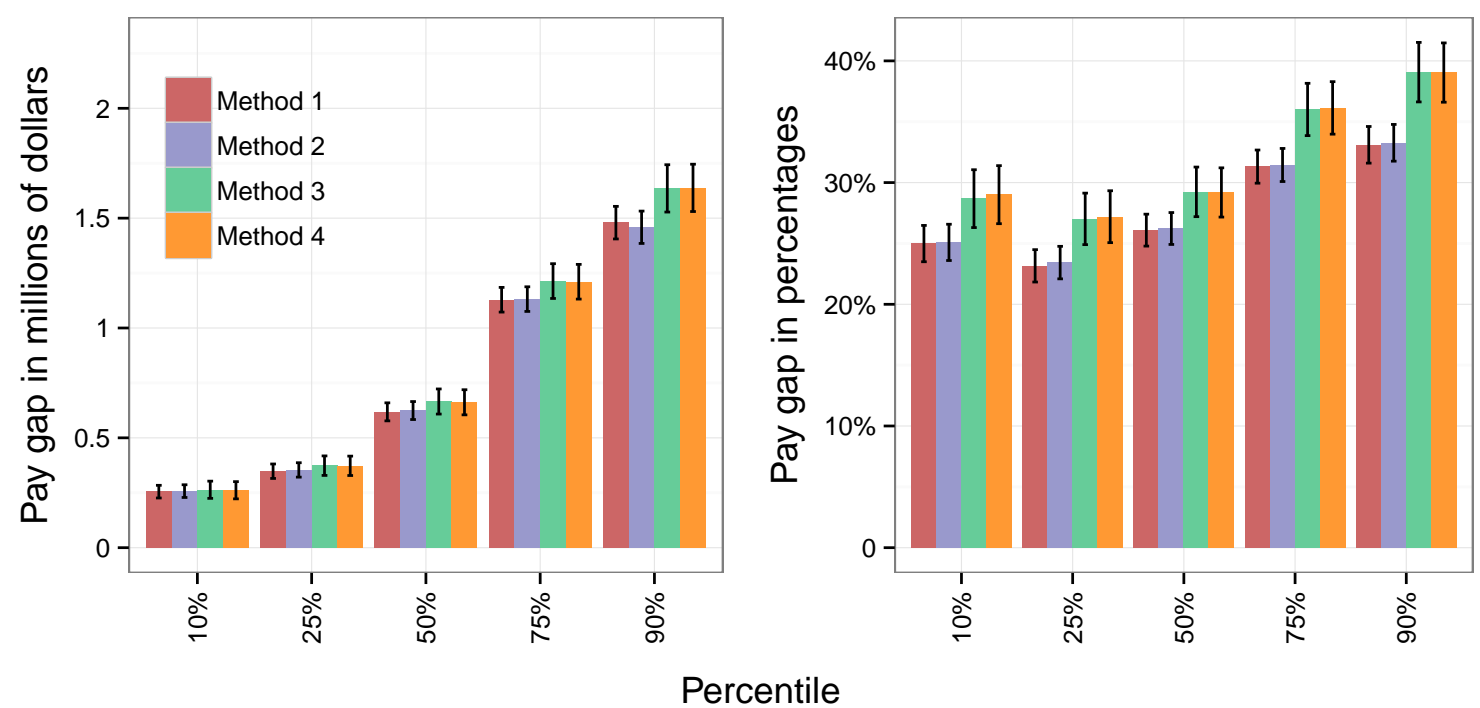

Note: The panel on the left plots the estimates of the differences between the named and natural peer groups for each of the 4 methods in millions of dollars at the $10^{t h}, 25^{t h}, 50^{t h}, 75^{t h}$ and $90^{t h}$ percentile of the compensation distribution of the peer group. In other words, it plots the difference in pay between the CEO of the firm at the $10^{t h}, 25^{t h}$, etc. percentile of the named and the natural peer group. The panel on the right plots the estimates of the differences between the named and natural peer group for each of the 4 methods in percentages at the $10^{\text {th }}, 25^{\text {th }}, 50^{\text {th }}, 75^{\text {th }}$ and $90^{\text {th }}$ percentiles. 
Figure 4: Distribution of the Median Peer Pay Effect: The Difference Between the Median Peer Compensation in the Named Peer Group and the Simulated Peer Group.

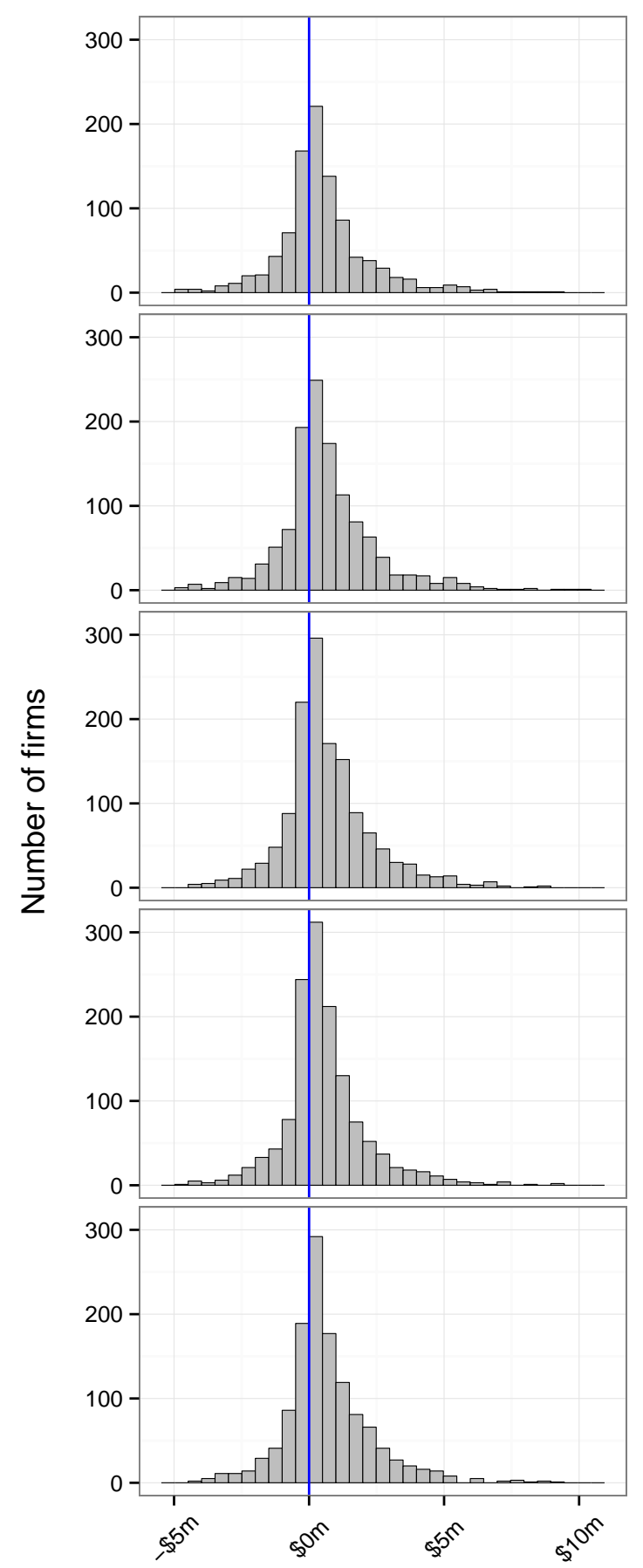

Pay gap in dollars

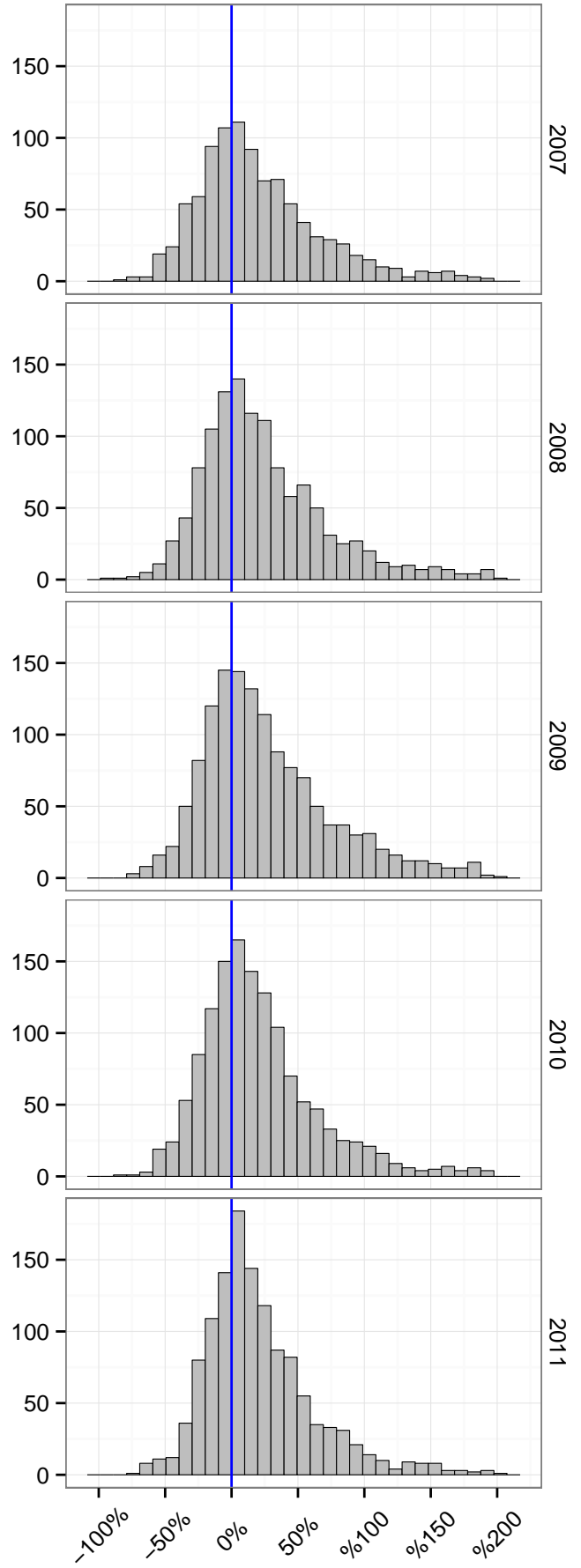

Pay gap in percentages

Note: The panel on the left plots the estimates in dollars for each of the five years, while the panel on the right plots the estimate as a percentage of the median compensation in the simulated peer group. 
Figure 5: Comparison of peer group bias and the pay percentile at which the focal CEO is compensated
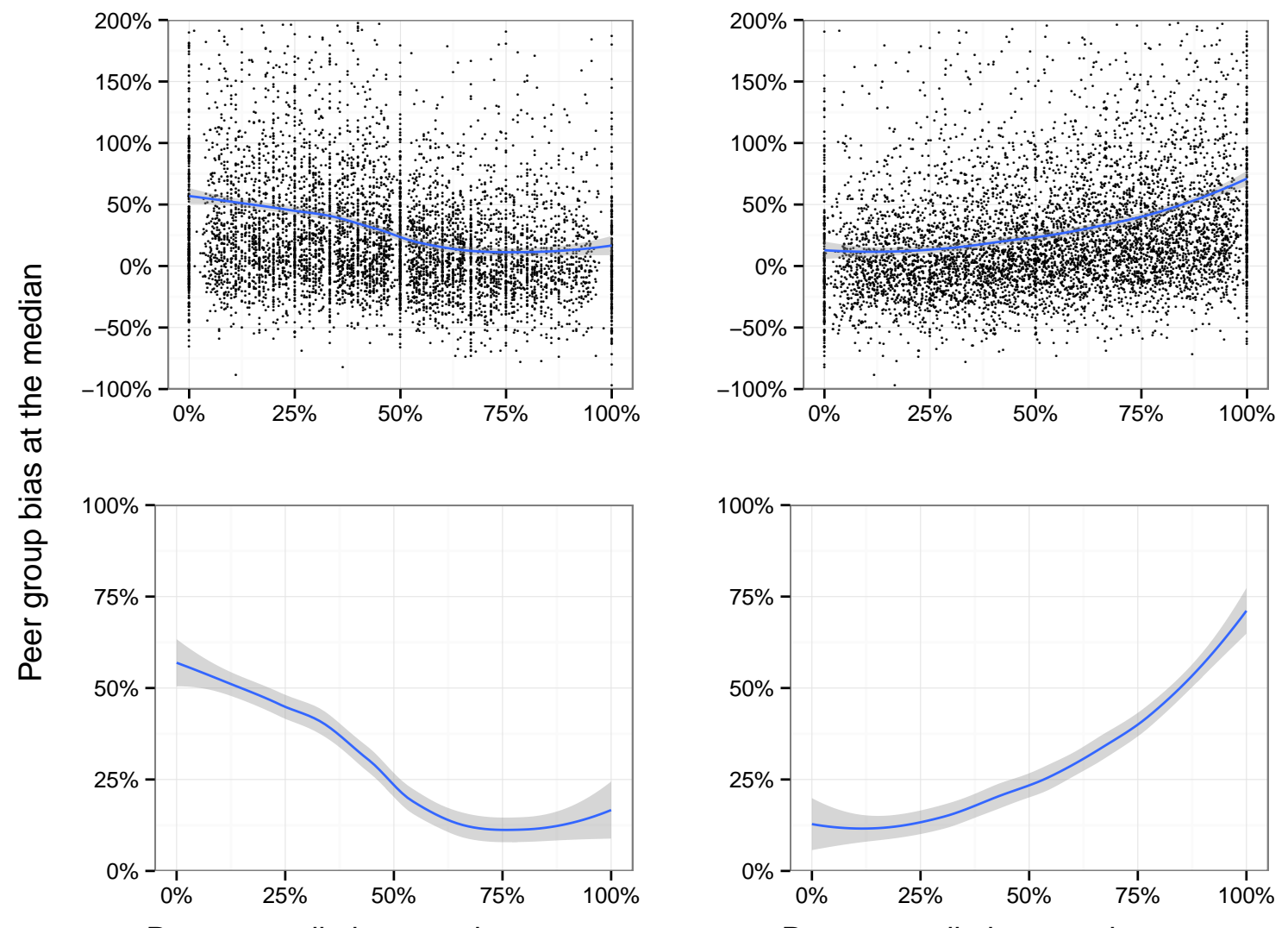

Pay percentile in named peer group

Pay percentile in natural peer group

Note: The two left panels show the scatter plot and Loess regression line for the relation between peer group bias and the pay percentile in the named peer group at which the focal CEO is compensated. The lower left panel zooms in on the Loess curve to better show the detailed behavior of the curve. The two right panels show the scatter plot and Loess regression line for the relation between peer group bias and the pay percentile in the natural peer group at which the focal CEO is compensated. Note that in both graphs some outliers that have a percentage bias that is larger than $200 \%$ are not shown for presentation purposes. 
Figure 6: Regressions of the Peer Pay Effect and the Pay Percentile on Managerial Ability
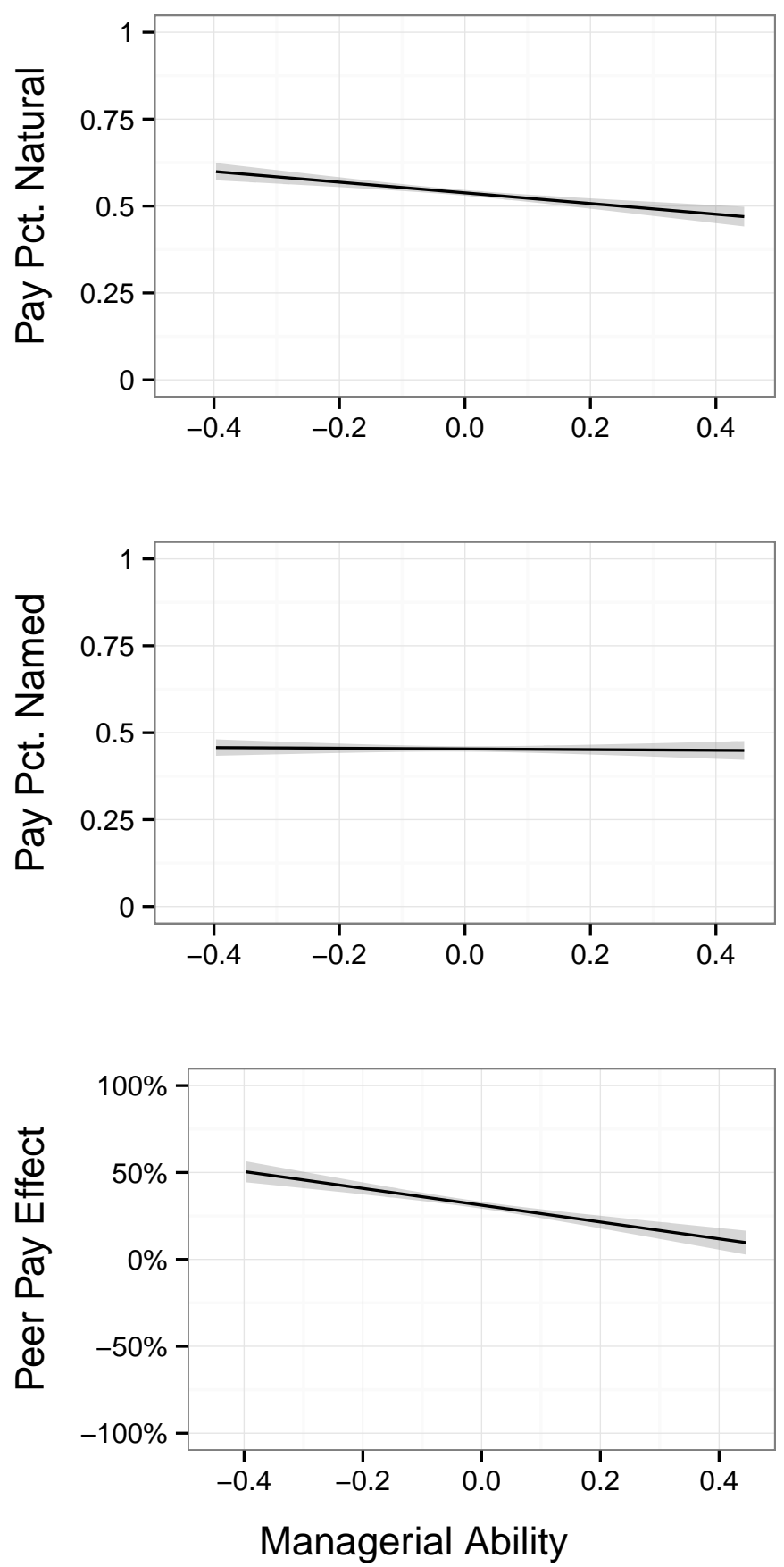

Note: Each panel shows the estimated regression line for a regression of the variable on the y-axis on Managerial Ability. From top to bottom, the variables on the y-axis are Pay Percentile Natural, Pay Percentile Named, and Peer Pay Effect. The grey bounds around the black lines are the confidence bounds. 
Figure 7: The interactive effect of Popularity and $\log ($ Peer Compensation) on peer removal.

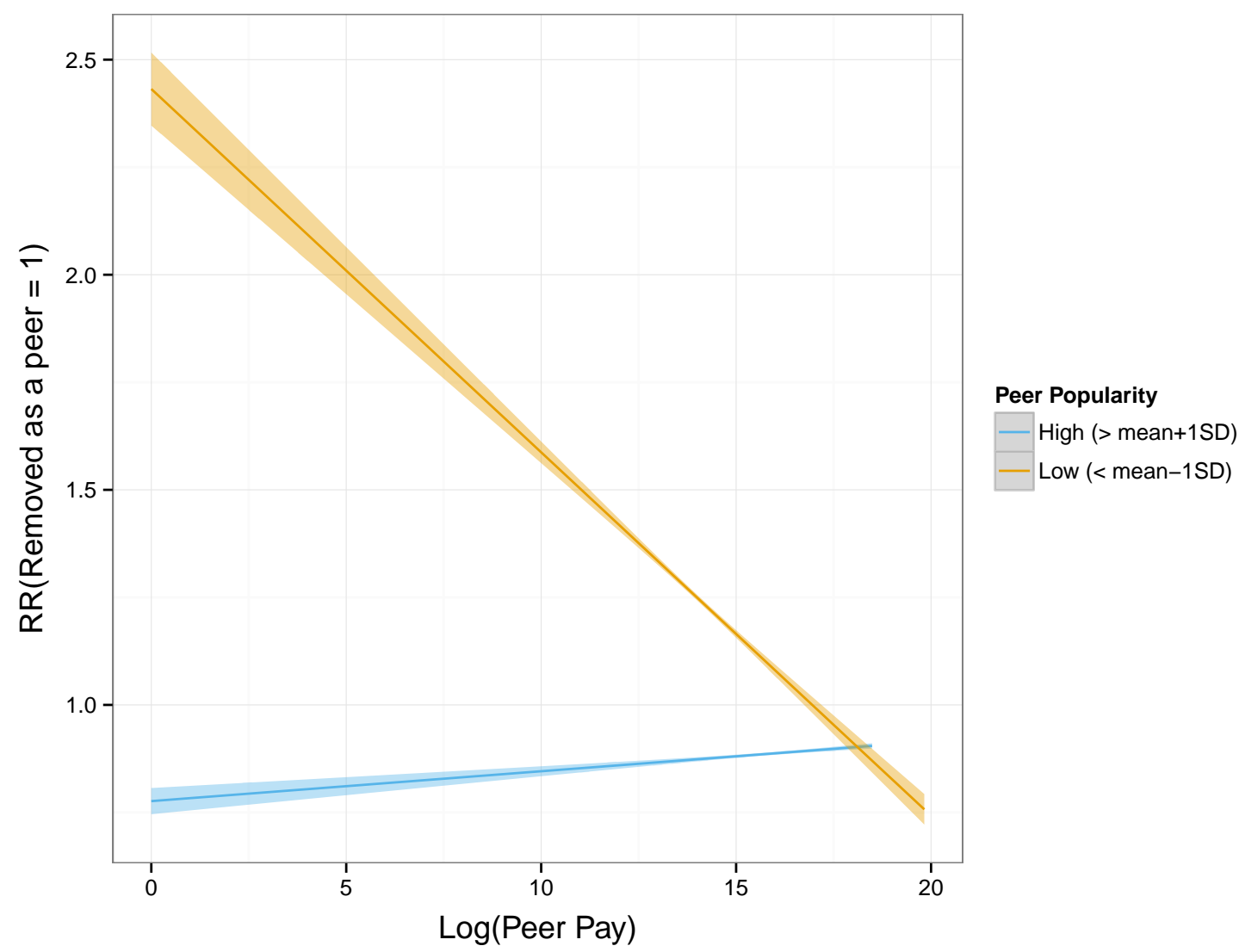

Note: The y-axis shows the relative risk of a peer being removed from a peer group. More precisely, it shows the risk of removal relative to the stratum average. The $\mathrm{x}$-axis plots the range for $\log$ (Peer Compensation) and the two lines distinguish between popular peers and unpopular peers. These two groups are identified by computing mean popularity and its standard deviation. Popular peers are defined as those more popular than mean(popularity) $+\operatorname{sd}($ popularity), while unpopular peers are defined as those less popular than mean(popularity) - sd(popularity). The lines are fitted as linear regressions through the relative risk of removal and $\log ($ Peer Compensation). 
Figure 8: The interactive effect of Popularity and Log(Peer Compensation) on peer addition.

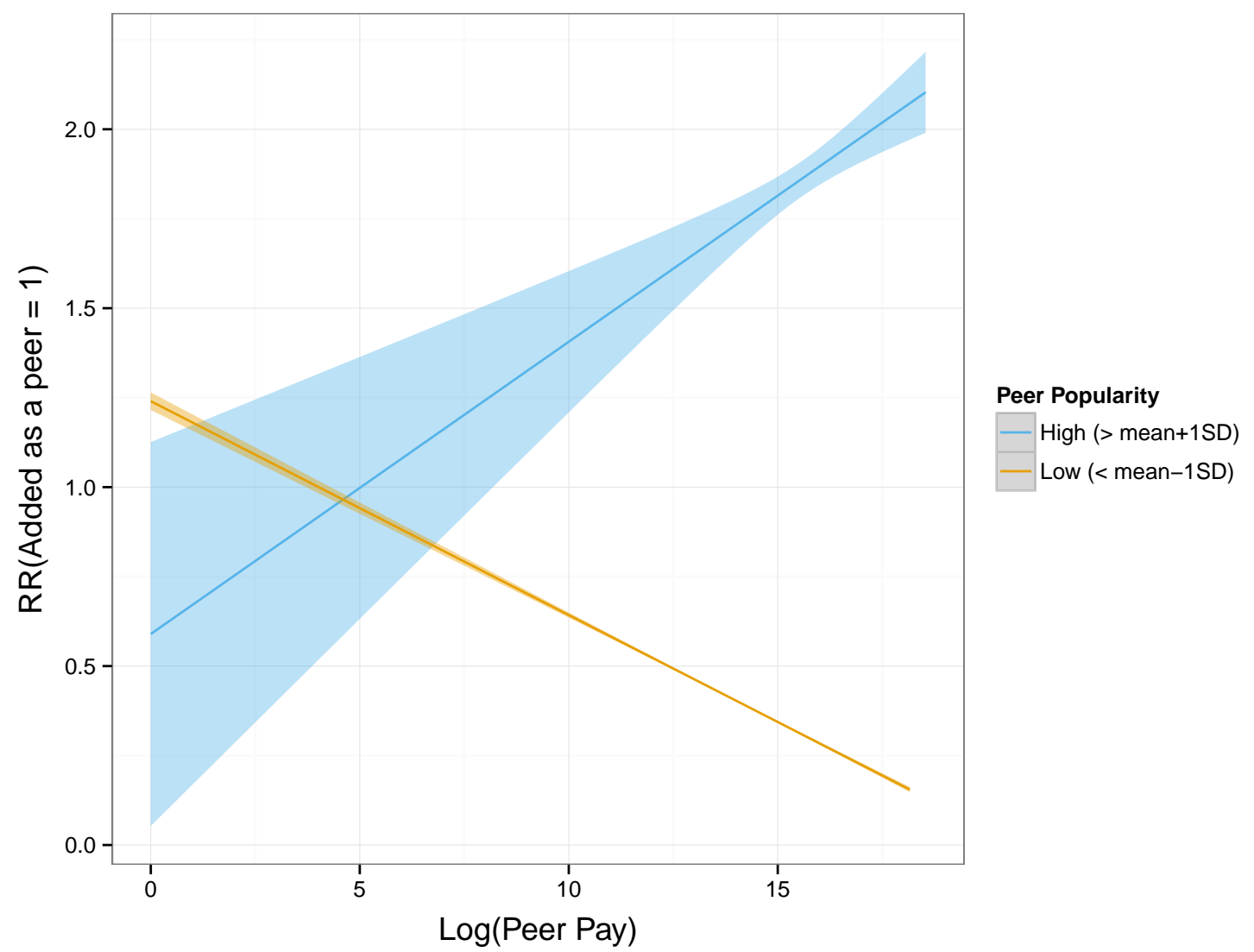

Note: The y-axis shows the relative risk of a peer being added to a peer group. More precisely, it shows the risk of addition relative to the stratum average. The $\mathrm{x}$-axis plots the range for $\log$ (Peer Compensation) and the two lines distinguish between popular peers and unpopular peers. These two groups are identified by computing mean popularity and its standard deviation. Popular peers are defined as those more popular than mean(popularity) + sd(popularity), while unpopular peers are defined as those less popular than mean(popularity) - sd(popularity). The lines are fitted as linear regressions through the relative risk of addition and $\log$ (Peer Compensation). 
Table 1: Summary statistics, standard errors below means.

\begin{tabular}{llllll}
\hline & 2007 & 2008 & 2009 & 2010 & 2011 \\
\hline Size & & & & & \\
Firms reporting peers & 1054 & 1265 & 1443 & 1381 & 1288 \\
Peer group size (mean) & 19.03 & 18.81 & 18.65 & 18.66 & 18.51 \\
& 0.32 & 0.28 & 0.25 & 0.26 & 0.27 \\
25th pct. & 13 & 13 & 13 & 13 & 13 \\
50th pct. & 17 & 17 & 17 & 17 & 17 \\
75th pct. & 22 & 22 & 21 & 21 & 21 \\
Change in \% & & & & & \\
Change in peer group & NA & 74.57 & 73.36 & 73.28 & 71.66 \\
Peers added & NA & 19.1 & 15.85 & 16.44 & 16.4 \\
& NA & 0.73 & 0.62 & 0.6 & 0.61 \\
Peers removed & NA & 18.37 & 16.59 & 16.77 & 17.01 \\
& NA & 0.69 & 0.58 & 0.58 & 0.6 \\
\hline
\end{tabular}


Table 2: Correlation coefficients and descriptive statistics

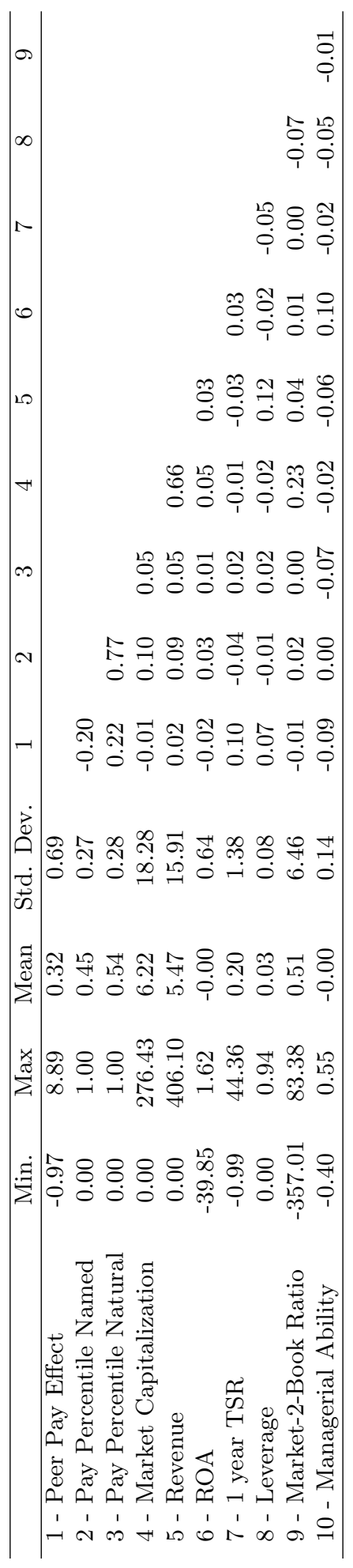


Table 3: Coefficient estimates of predictors of peer group bias

\begin{tabular}{|c|c|c|c|c|c|c|}
\hline & Model 1 & Model 2 & Model 3 & Model 4 & Model 5 & Model 6 \\
\hline Pay Pct. Natural & & & $\begin{array}{c}.511^{* * *} \\
(.035)\end{array}$ & & & $\begin{array}{c}.314^{* * *} \\
(.033)\end{array}$ \\
\hline Pay Pct. Named & & $\begin{array}{c}-.516^{* * *} \\
(.037)\end{array}$ & & & $\begin{array}{c}-.358^{* * *} \\
(.034)\end{array}$ & \\
\hline Market Capitalization & $\begin{array}{l}-.001 \\
(.001)\end{array}$ & $\begin{array}{l}-.001 \\
(.001)\end{array}$ & $\begin{array}{l}-.001 \\
(.001)\end{array}$ & $\begin{array}{l}.001 \\
(.002)\end{array}$ & $\begin{array}{c}.001 \\
(.002)\end{array}$ & $\begin{array}{c}.001 \\
(.002)\end{array}$ \\
\hline Revenue & $\begin{array}{l}.001 \\
(.001)\end{array}$ & $\begin{array}{l}.002^{*} \\
(.001)\end{array}$ & $\begin{array}{l}.001 \\
(.001)\end{array}$ & $\begin{array}{c}-.010^{* *} \\
(.004)\end{array}$ & $\begin{array}{c}-.010^{* *} \\
(.004)\end{array}$ & $\begin{array}{c}-.010^{* *} \\
(.004)\end{array}$ \\
\hline $\mathrm{ROA}$ & $\begin{array}{l}-.013 \\
(.016)\end{array}$ & $\begin{array}{l}-.007 \\
(.016)\end{array}$ & $\begin{array}{l}-.015 \\
(.016)\end{array}$ & $\begin{array}{l}-.022 \\
(.020)\end{array}$ & $\begin{array}{l}-.013 \\
(.020)\end{array}$ & $\begin{array}{l}-.029 \\
(.020)\end{array}$ \\
\hline 1 year TSR & $\begin{array}{c}.050^{* * *} \\
(.007)\end{array}$ & $\begin{array}{c}.046^{* * *} \\
(.007)\end{array}$ & $\begin{array}{c}.048^{* * *} \\
(.007)\end{array}$ & $\begin{array}{c}.036^{* * *} \\
(.005)\end{array}$ & $\begin{array}{c}.033^{* * *} \\
(.005)\end{array}$ & $\begin{array}{l}.034^{* * *} \\
(.005)\end{array}$ \\
\hline Leverage & $\begin{array}{c}.541^{* * *} \\
(.129)\end{array}$ & $\begin{array}{l}.513^{* * *} \\
(.127)\end{array}$ & $\begin{array}{c}.510^{* * *} \\
(.126)\end{array}$ & $\begin{array}{c}.122 \\
(.136)\end{array}$ & $\begin{array}{l}.100 \\
(.134)\end{array}$ & $\begin{array}{l}.130 \\
(.134)\end{array}$ \\
\hline Market-2-Book Ratio & $\begin{array}{c}.000 \\
(.002)\end{array}$ & $\begin{array}{c}.000 \\
(.002)\end{array}$ & $\begin{array}{c}.000 \\
(.002)\end{array}$ & $\begin{array}{c}.006^{* * *} \\
(.001)\end{array}$ & $\begin{array}{c}.006^{* * *} \\
(.001)\end{array}$ & $\begin{array}{l}.005^{* * *} \\
(.001)\end{array}$ \\
\hline Managerial Ability & $\begin{array}{c}-.410^{* * *} \\
(.072)\end{array}$ & $\begin{array}{c}-.412^{* * *} \\
(.070)\end{array}$ & $\begin{array}{c}-.344^{* * *} \\
(.070)\end{array}$ & $\begin{array}{c}-.201^{*} \\
(.097)\end{array}$ & $\begin{array}{c}-.215^{*} \\
(.095)\end{array}$ & $\begin{array}{l}-.170 \\
(.096)\end{array}$ \\
\hline Intercept & $\begin{array}{c}.284^{* * *} \\
(.012)\end{array}$ & $\begin{array}{c}.515^{* * *} \\
(.020)\end{array}$ & $\begin{array}{c}.013 \\
(.022) \\
\end{array}$ & & & \\
\hline $\mathrm{R}^{2}$ & .023 & .063 & .067 & .022 & .052 & .046 \\
\hline Adj. $R^{2}$ & .021 & .062 & .065 & .017 & .040 & .035 \\
\hline Num. obs. & 4,606 & 4,606 & 4,606 & 4,606 & 4,606 & 4,606 \\
\hline
\end{tabular}

Note: Model 1 - 3 are pooled OLS regressions. Model 4 - 6 are OLS regressions with fixed effects for the firms in the data. F-tests comparing model 1 and 4, 2 and 5, and 3 and 6 indicate that the fixed effects are jointly significant (F-statistics are 6.2, 6.1, and 5.9 respectively.) 
Table 4: Correlation coefficients and descriptive statistics

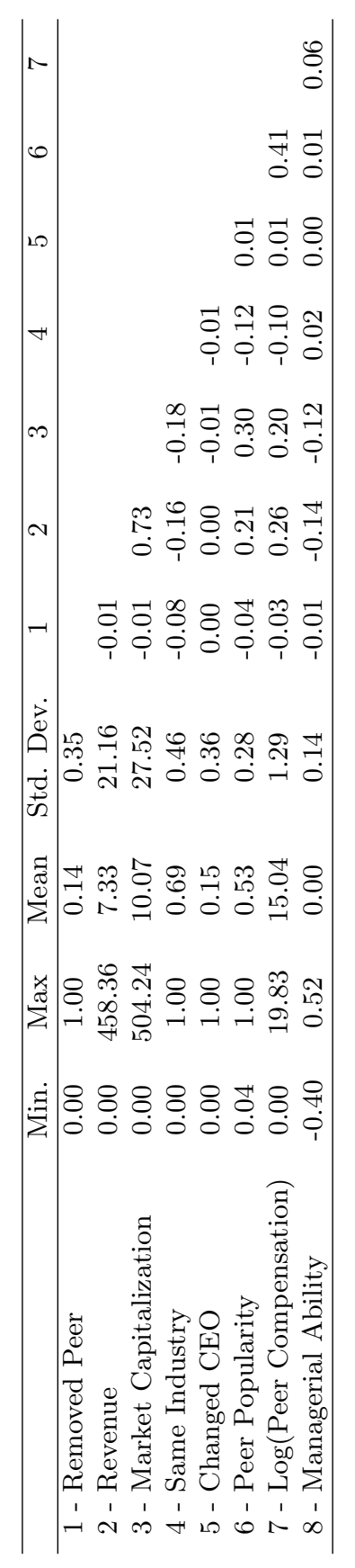


Table 5: Conditional Logistic Regression

Dependent variable: Removal from peer group

\begin{tabular}{|c|c|c|c|c|c|c|}
\hline & Model 1 & Model 2 & Model 3 & Model 4 & Model 5 & Model 6 \\
\hline Revenue & $.002^{*}$ & .000 & .000 & .000 & .000 & .000 \\
\hline & $(.001)$ & $(.001)$ & $(.001)$ & $(.001)$ & $(.001)$ & $(.001)$ \\
\hline Market Capitalization & $-.002^{* *}$ & -.001 & -.001 & -.001 & -.001 & -.001 \\
\hline & $(.001)$ & $(.001)$ & $(.001)$ & $(.001)$ & $(.001)$ & $(.001)$ \\
\hline Same Industry & $\begin{array}{c}-.672^{* * *} \\
(.032)\end{array}$ & $\begin{array}{c}-.697^{* * *} \\
(.032)\end{array}$ & $\begin{array}{c}-.696^{* * *} \\
(.032)\end{array}$ & $\begin{array}{c}-.646^{* * *} \\
(.035)\end{array}$ & $\begin{array}{c}-.695^{* * *} \\
(.032)\end{array}$ & $\begin{array}{c}-.695^{* * *} \\
(.032)\end{array}$ \\
\hline Changed CEO & $\begin{array}{l}.116^{* *} \\
(.044)\end{array}$ & $\begin{array}{l}.130^{* *} \\
(.044)\end{array}$ & $\begin{array}{l}.129^{* *} \\
(.044)\end{array}$ & $\begin{array}{l}.147^{* *} \\
(.050)\end{array}$ & $\begin{array}{l}.129^{* *} \\
(.044)\end{array}$ & $\begin{array}{c}-.898^{*} \\
(.381)\end{array}$ \\
\hline Log(Peer Compensation $)$ & $\begin{array}{c}-.038^{* * *} \\
(.009)\end{array}$ & $\begin{array}{l}-.008 \\
(.010)\end{array}$ & $\begin{array}{l}-.007 \\
(.010)\end{array}$ & $\begin{array}{l}-.004 \\
(.011)\end{array}$ & $\begin{array}{c}-.057^{*} \\
(.025)\end{array}$ & $\begin{array}{l}-.018 \\
(.011)\end{array}$ \\
\hline Peer Popularity & & $\begin{array}{c}-.869^{* * *} \\
(.056)\end{array}$ & $\begin{array}{c}-1.532^{* *} \\
(.518)\end{array}$ & $\begin{array}{c}-1.495^{*} \\
(.601)\end{array}$ & $\begin{array}{c}-2.475^{* * *} \\
(.670)\end{array}$ & $\begin{array}{c}-1.541^{* *} \\
(.518)\end{array}$ \\
\hline Peer Popularity ${ }^{2}$ & & & $\begin{array}{c}1.225 \\
(1.119)\end{array}$ & $\begin{array}{c}1.521 \\
(1.280)\end{array}$ & $\begin{array}{c}1.057 \\
(1.121)\end{array}$ & $\begin{array}{c}1.252 \\
(1.119)\end{array}$ \\
\hline Peer Popularity $^{3}$ & & & $\begin{array}{l}-.651 \\
(.711)\end{array}$ & $\begin{array}{l}-.879 \\
(.803)\end{array}$ & $\begin{array}{l}-.641 \\
(.711)\end{array}$ & $\begin{array}{l}-.671 \\
(.711)\end{array}$ \\
\hline Managerial Ability & & & & $\begin{array}{c}-.234^{*} \\
(.099)\end{array}$ & & \\
\hline Peer Popularity * Log(Peer Compensation $)$ & & & & & $\begin{array}{l}.075^{*} \\
(.034)\end{array}$ & \\
\hline CEO Change $*$ Log $($ Peer Compensation $)$ & & & & & & $\begin{array}{l}.068^{* *} \\
(.025) \\
\end{array}$ \\
\hline AIC & 41228.725 & 40990.424 & 40992.240 & 30897.866 & 40989.226 & 40986.532 \\
\hline Num. events & 14,709 & 14,709 & 14,709 & 11,246 & 14,709 & 14,709 \\
\hline Num. obs. & 111,221 & 111,221 & 111,221 & 85,695 & 111,221 & 111,221 \\
\hline
\end{tabular}


Table 6: Correlation coefficients and descriptive statistics

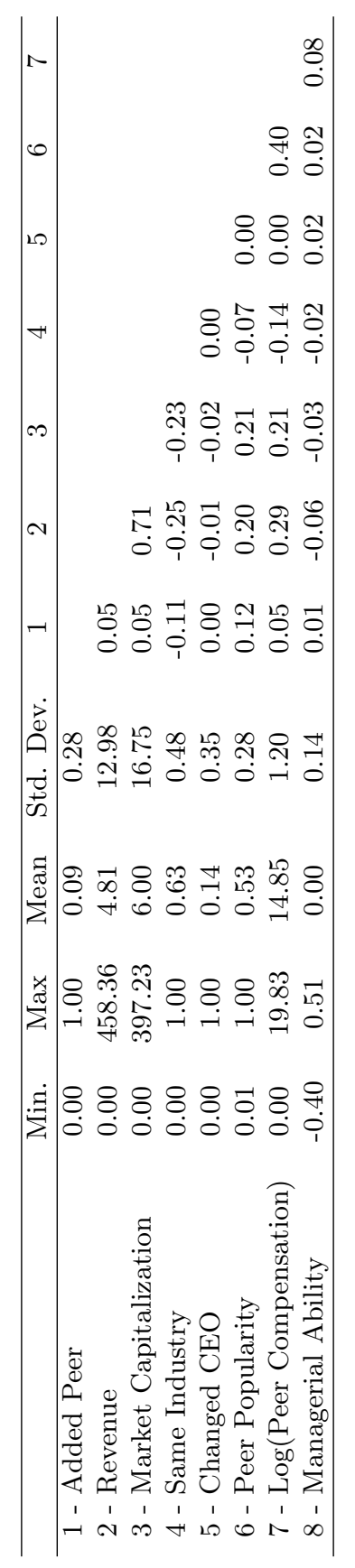


Table 7: Conditional Logistic Regression

Dependent variable: Addition to peer group

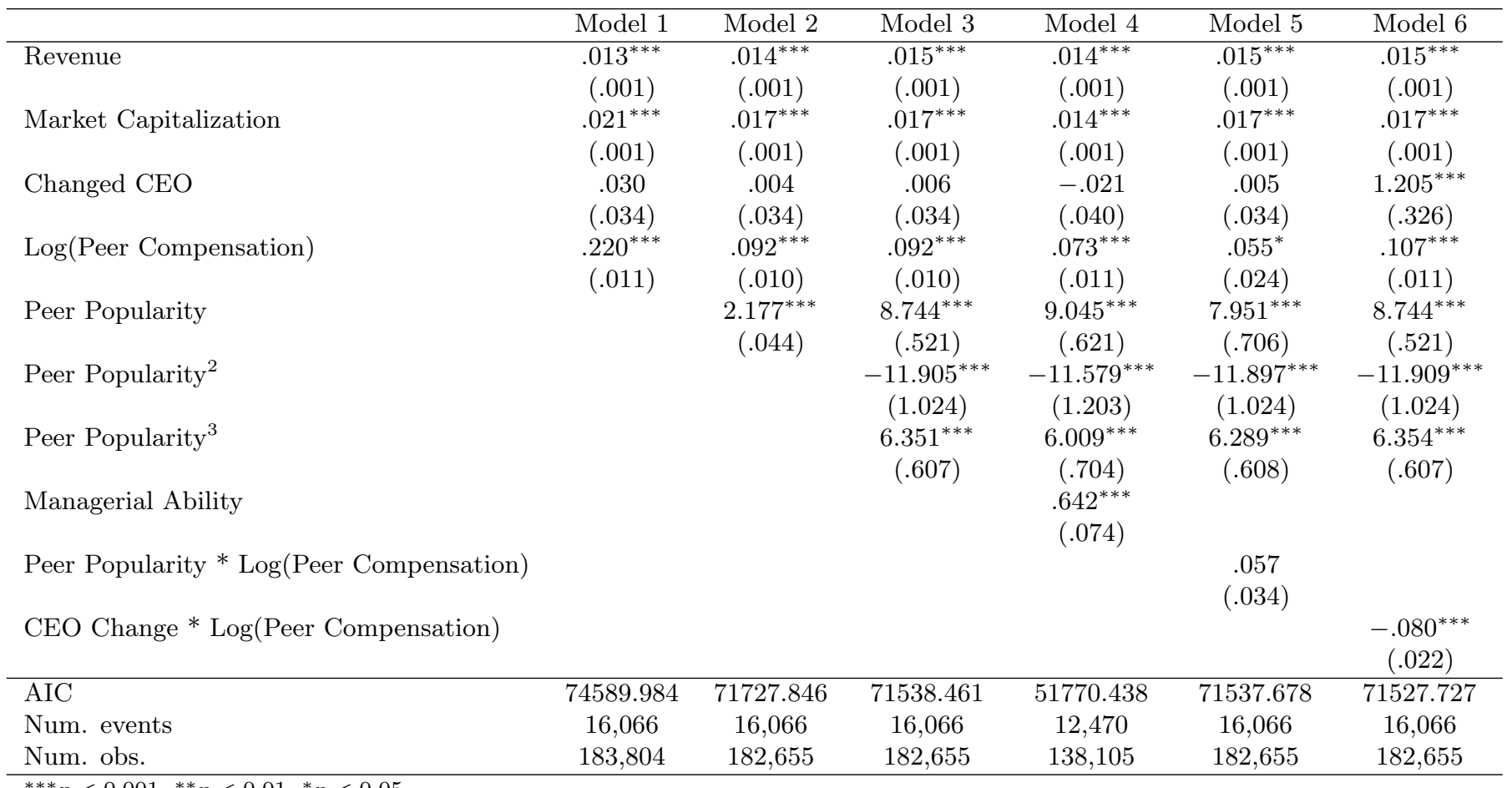




\section{Appendices}

\section{A Variable Definitions}

In Table A1 we report the variable definitions and the sources used to compute the variables. These variables are introduced throughout the paper. We used three sources: Peer ID (the author developed peer group harvest algorithm), Compustat, Morningstar/Execucomp, and Dow Jones data.

\section{B Median peer pay effect from PSM method}

Figure B1 shows the distribution of the median peer pay effect using the Propensity Score Matching method. The yearly correlation of the median peer pay effect for the preferred simulation method and the PSM method is 0.48 in 2007, 0.55 in 2008, 0.52 in 2009, 0.55 in 2010, and 0.50 in 2011. All analyses in this paper are also replicated using the PSM estimate of the peer pay effect. While the precise estimates of the regression coefficients differ from the regression coefficients using the simulation method, the significance and direction of our main variables are similar. The regression tables containing those estimates are available from the authors. 
Figure B1: Distribution of the median peer pay effect: The difference between the median peer compensation in the named peer group and the simulated peer group.

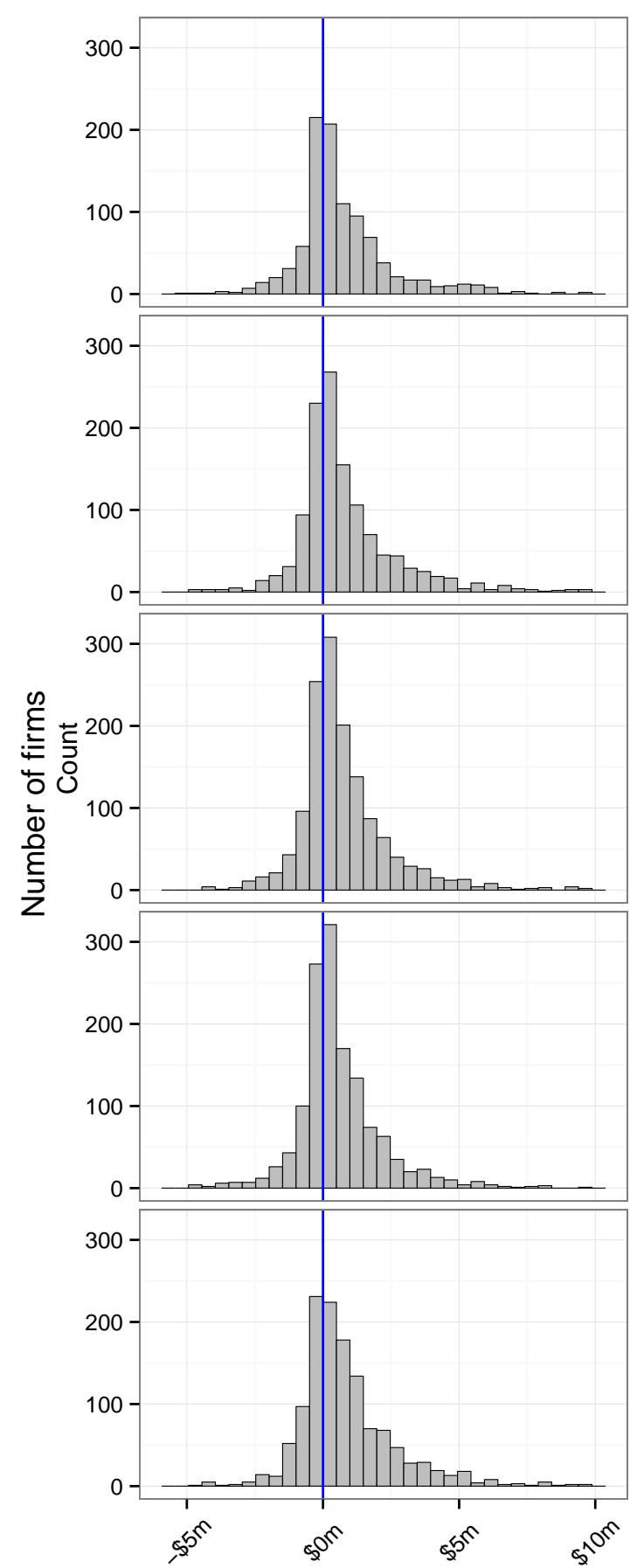

Pay gap in dollars

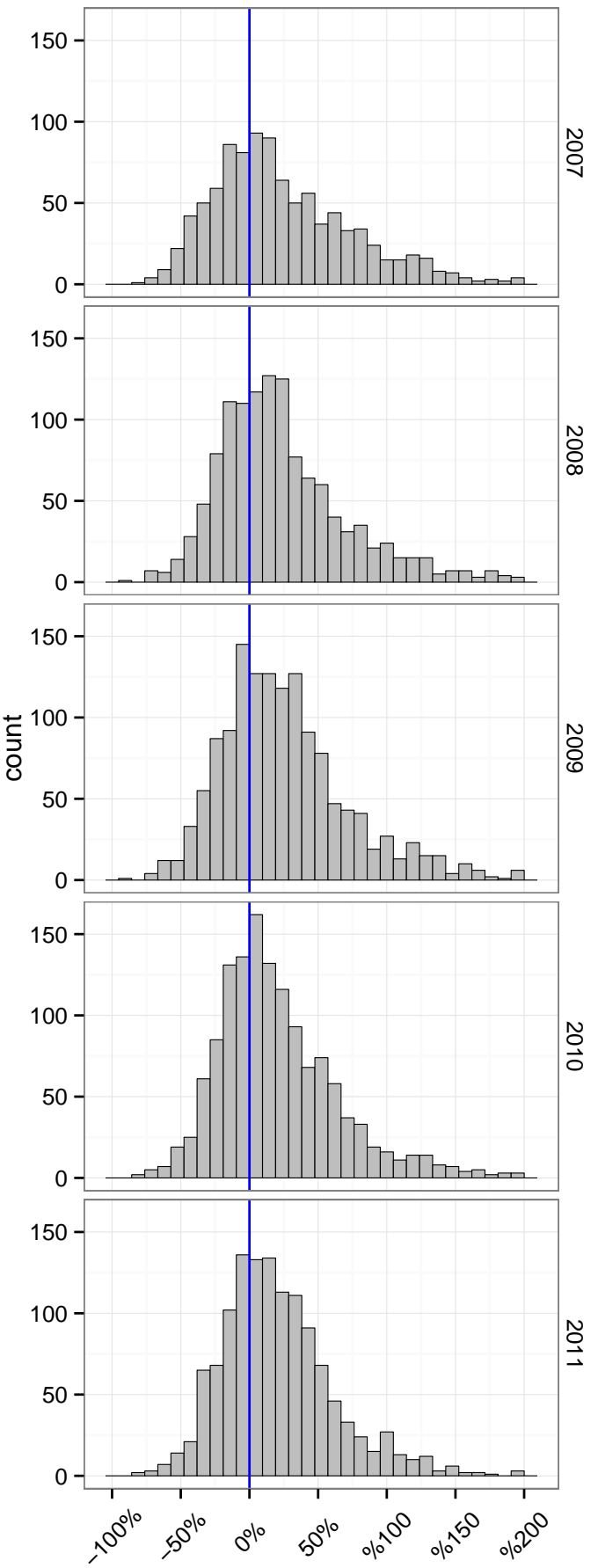

Pay gap in percentages

Note: The panel on the left plots the estimates in dollars, the panel on the right plots the estimate as a percentage of the Median Compensation in the Simulated Peer Group. 


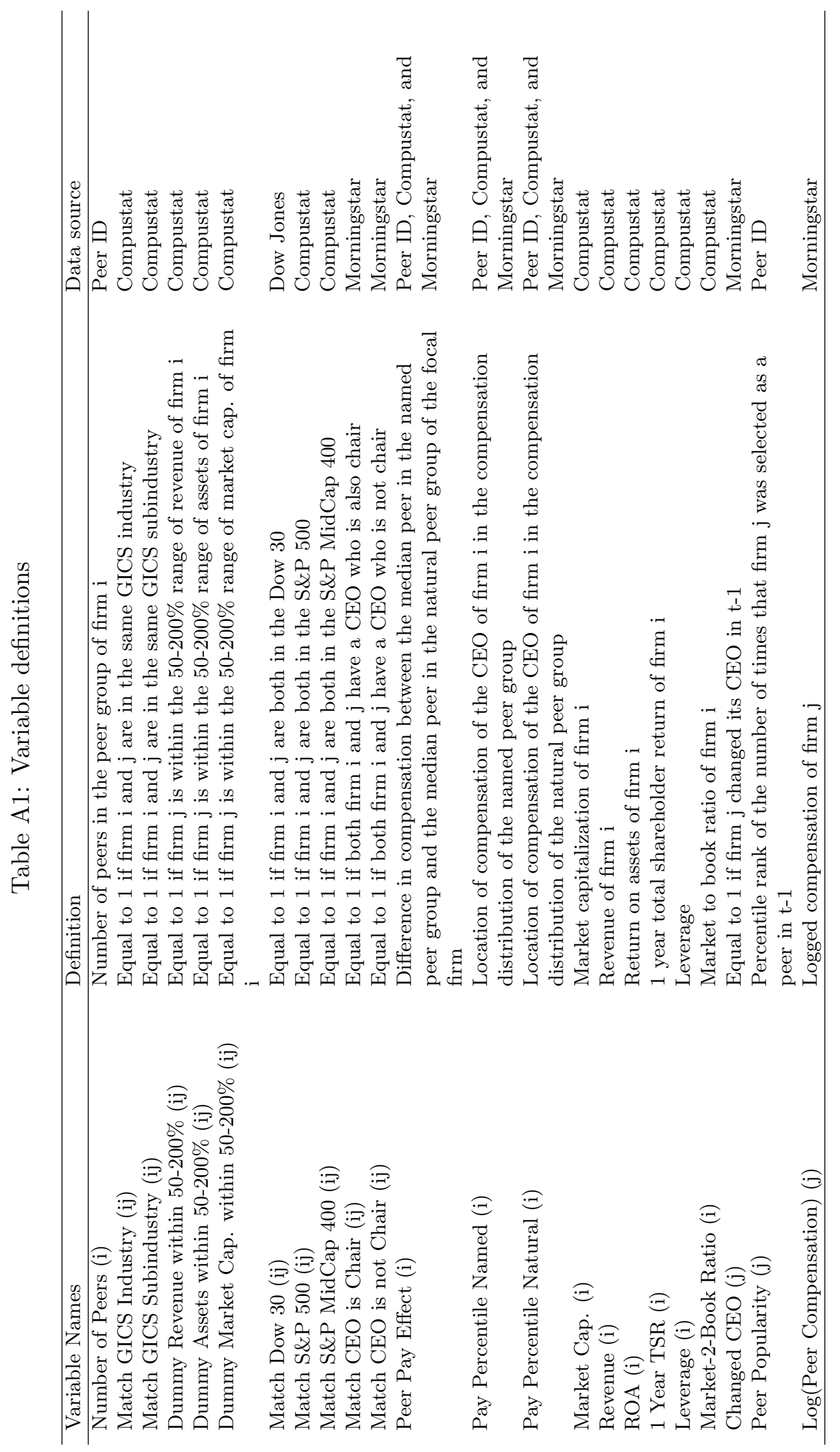

